RECTIED

HAY 05 १९SE

OS.TI

\title{
TECHNETIUM BEHAVIOR AND RECOVERY IN SOIL
}

\author{
George E. Meinken
}

December, 1995

\section{- DISCLAIMER}

\begin{abstract}
This report was prepared as an account of work sponsored by an agency of the United States Government. Neither the United States Government nor any agency thereof, nor any of their employees, makes any warranty, express or implied, or assumes any legal liability or responsibility for the accuracy, completeness, or usefulness of any information, apparatus, product, or process disclosed, or represents that its use would not infringe privately owned rights. Reference herein to any specific commercial product, process, or service by trade name, trademark, manufacturer, or otherwise does not necessarily constitute or imply its endorsement, recommendation, or favoring by the United States Government or any agency thereof. The views and opinions of authors expressed herein do not necessarily state or reflect those of the United States Government or any agency thereof.
\end{abstract}

Brookhaven National Laboratory

Building 801, Medical Department

P.O. Box 5000

Upton, NY 11973-5000

(516) 344-4453; FAX: (516) 344-5962 


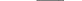


TECHNETIUM BEHAVIOR AND RECOVERY IN SOIL

Thesis Project

for the Degree of

Master of Science in Environmental Technology

George E. Meinken

December, 1995 
I would like to acknowledge the helpful guidance of New York Institute of Technology professors, Dr. S. Greenwald and Dr. W. Graner throughout the course of this program and thesis.

The work undertaken in this thesis would not have been possible without the many helpful people at Brookhaven National Laboratory. Dr. A.J. Francis and Cleveland Dodge suggested the project for the thesis and provided valuable guidance and financial support throughout the work. My colleagues, specifically, Dr. Leonard Mausner and Slawko Kurczak provided the irradiation and processing of technetium-95m. Mark Fuhrmann supplied me with many useful references. My supervisor Dr. Suresh Srivastava allowed me to use our excellent radiological facilities and allowed flexibility in my work schedule to interact with Dr. Francis and Cleveland Dodge. Dr. John Gatley was extremely helpful with suggestions for liquid scintillation counting. Susan Cataldo and Thomas Martin were invaluable in preparing the manuscript. Dr. Mark Sweet supplied me with freshly distilled solvents and the special glassware needed for many of the experiments.

Marylin Pandorf of the Brookhaven National Laboratory personnel department should be complimented for the efficient coordination of this program between Brookhaven National Laboratory and New York Institute of Technology

It is essential to recognize the role in this program provided by Brookhaven National Laboratory and Associated Universities, Inc. BNL is an excellent research facility where one can grow professionally with an atmosphere conducive to 
creativity. BNL has always encouraged employees to further their education. In doing so, a more creative, productive and safety conscious staff has resulted. 
TECHNETIUM BEHAVIOR AND RECOVERY

IN SOIL

Thesis Project
Submitted in Partial Fulfillment of the Requirements of the
Degree of

Master of Science in Environmental Technology

at the

New York Institute of Technology

Old Westbury, New York

by

George E. Meinken

Copy No.

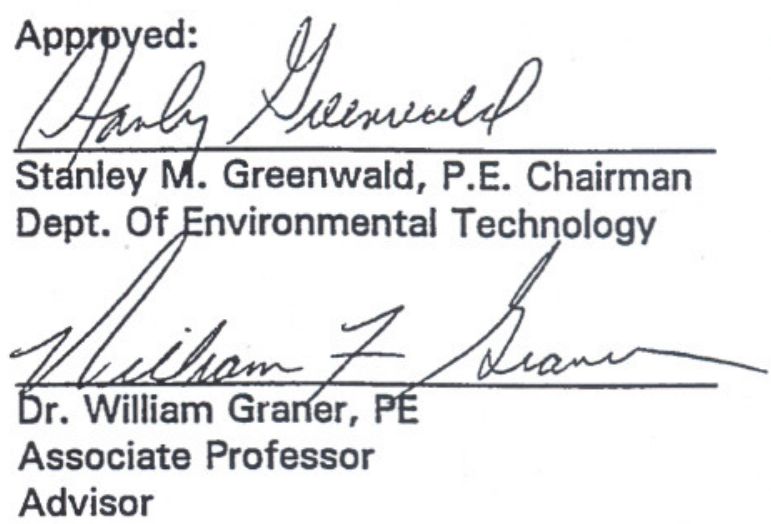




\begin{abstract}
Technetium-99 in soils is of great concern because of its long half-life and because it can not be detected readily. This work reviews the behavior of technetium in various types of soils. A method for extracting technetium from soil was developed with the use of technetium-95m and $99 \mathrm{~m}$ to determine recoveries at each step. Technetium chemistry is very complicated and problem areas in the behavior and recovery have been highlighted. Technetium is widely used in nuclear medicine and a review of its chemistry pertaining to radiopharmaceuticals is relevant and helpful in environmental studies.

The technetium behavior in the patented citric acid method for the removal of toxic metals in contaminated soils was studied. An innovative method using solid phase extraction media for the concentration of technetium extracted from soils, with water and hydrogen peroxide, was developed. This technique may have a useful environmental application for this type of remediation of technetium from contaminated soils.
\end{abstract}


Chapter $1:$ Introduction $\ldots \ldots \ldots \ldots \ldots \ldots \ldots \ldots \ldots \ldots \ldots$ 1-3

Chapter 2: Literature Review . . . . . . . . . . . . . 4-13

Chapter 3: Investigative Procedure . . . . . . . . . . . . 14

Equipment, Reagents, Radioisotopes ............... 14-15

3.1 Production of Technetium-95m . . . . . . . . 15-16

3.2 Characterization and Formation of .......... 16-17

Technetium Citrate at $\mathrm{pH} 3$ and $\mathrm{pH} 6$

3.2.1 Reduction of pertechnetate $\left({ }^{99} \mathrm{TcO}_{4}{ }^{\circ}\right) \ldots \ldots \ldots$ 16-17 to hexachlorotechnetate $\left(\mathrm{TcCl}_{6}\right)^{-2}$

3.2.2 Complexation experiments with citrate . . . . 17-22

3.3 Soil Characterization . . . . . . . . . . . 22-26

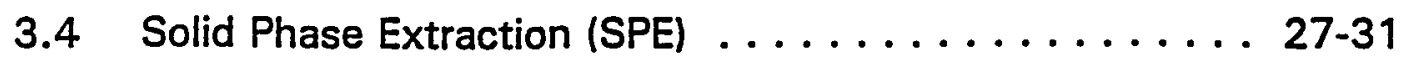
for Technetium Concentration

3.5 Pertechnetate Extractions with . . . . . . . . 31-33 MEK from $2.5 \mathrm{~N} \mathrm{NaOH}$

3.6 Reducing Capability of Soils ............. 33

3.7 Counting Samples for Radioactivity . . . . . . . 34-38

3.8 Distillation of Technetium in Soils with ......... 38-39

3.9 Determination of ${ }^{99} \mathrm{Tc}$ Levels in Soils Studied . . . . . . . 40

3.9.1 Addition of Technetium-99m Tracer to ..... 40-43

3.9.2 Beta Response from Uranium-238 . . . . . . . 43-44

3.9.3 Extraction of Four Soils with Water/Hydrogen . . 45-46 Peroxide and Citric Acid/Hydrogen Peroxide with Second Digestion of Residual Soil

3.9.4 One Soil Extracted by Two Methods of Agitation . 46-48 of Different Times Without Hydrogen Peroxide

3.9.5 Fate of Technetium and Uranium During ... . . . 48-54 Bioremediation of Contaminated Soil, Using the BNL Citric Acid Process

4.0 Comparison of Technetium Soil Content . . . . . . . 5 54-56 with Independent Laboratory

Chapter 4: Results of Investigation . . . . . . . . . . . 57-60

Chapter 5: Conclusions . . . . . . . . . . . . . 61-64 
Appendix I: $\quad$ Amount of ${ }^{99} \mathrm{Tc}$ Produced from $\ldots \ldots \ldots \ldots 71$ a Patient Dose of 30 Millicuries of ${ }^{99 \mathrm{~m}} \mathrm{Tc}$

Appendix II: Calculation of Specific Activity of ${ }^{99} \mathrm{Tc} \ldots \ldots \ldots 72$

Appendix III: Detection of ${ }^{99} \mathrm{Tc}$ in HPLC U.V. Flow Cell . . . . . 73

Appendix IV: Isotopes Produced in the Irradiation $\ldots \ldots \ldots \ldots 73$ and Production of ${ }^{95 \mathrm{~m}} \mathrm{Tc}$ 


\section{List of Tables}

Table 1

PAGE

Technetium Isotopes Used and Physical Characteristics $\ldots \ldots \ldots 16$

\section{Table 2}

Technetium Citrate Yields Produced by Reduction with $\ldots \ldots \ldots 22$ Stannous or $\mathrm{HCl} / \mathrm{KI}$, Determined by The Use of Sephadex

Table 3

Soil Classification Based on Particle Size . . . . . . . . . . 25

Table 4

Physical Characteristic and Grain Size Distribution . . . . . . . 25 of Studied Soils

\section{Table 5}

Comparison of ${ }^{99} \mathrm{Tc}$ Concentration of for Water and . . . . . . 46 Citric Acid Extracted Soils

Table 6

Separatory Funnel Agitation Versus Wrist Action . . . . . . . . 47 Shaker Extraction of ${ }^{99}$ Tc From Soil 27227

\section{Table 7}

Comparison of Technetium Results for Contaminated Soils . . . . . 54 
Figure 1

Absorption Spectra of Perrhenate and Pertechnetate $\left(\mathrm{TCO}_{4}^{-}\right) \ldots \ldots 8$

Figure 2

Absorption Spectra of Hexachlororhenate and $\ldots \ldots \ldots \ldots . \ldots 9$ hexachlorotechnetate $\left(\mathrm{TcCl}_{6}\right)^{-2}$

Figure 3

Hexachlorotechnetate $\left(2.05 \times 10^{-4} \mathrm{M} \mathrm{TcCl}_{2}\right)^{-2}$ in $\ldots \ldots \ldots \ldots \ldots$

$2 \mathrm{M} \mathrm{HCl}$ Reduced in $\mathrm{HCl} / \mathrm{KI}$

Figure 4

$2.79 \times 10^{-4} \mathrm{M}^{99} \mathrm{Tc}$, Reduced with $\mathrm{HCL} / \mathrm{KI}$ and 30 fold (1) and $\ldots \ldots 19$ 100 fold (2) Molar Excess of Citrate pH 3, 24 hours at $37^{\circ} \mathrm{C}$.

Figure 5

Soil Grain Size Distribution of Soils Studied . . . . . . . . . . 24

Figure 6

Triangle of Soil Textures $\ldots \ldots \ldots \ldots \ldots \ldots \ldots \ldots \ldots$

Figure 7

Ion-Pairing for Reverse-Phase Separations $\ldots \ldots \ldots \ldots \ldots 28$

(Waters Associates Liquid Chromatography School)

Figure 8

Optimum Number of Counts for Minimizing Combined . . . . . . 36 Counting Time With Desired Relative Standard Deviation and Counter to Background Ratio

Figure 9

The Uranium Series $\ldots \ldots \ldots \ldots \ldots \ldots \ldots \ldots \ldots \ldots 4$

Figure 10

Remediation of $T c$ and $U$ Contaminated Soils . . . . . . . 49 Methods Procedure

Figure 11

Methods Procedure for ${ }^{99} \mathrm{Tc}$ Extraction from Soils $\ldots \ldots \ldots \ldots .62$ 


\section{Chapter 1}

\section{Introduction}

Nuclear power and the use of radioactivity in medicine provide enormous benefits to the general population. There is unwarranted fear of radioactivity, in part, I believe because of a lack of understanding. Because radiation can be measured so precisely its effects have been well studied. When one measures radioactivity one is measuring the effects of atom amounts of material. The effects of food additives or tobacco smoke can not be quantified so precisely, yet that is readily accepted by the public. Nevertheless, it is essential to have proper controls in place to monitor and remediate contamination as a result of the use of radioactivity.

Light water nuclear power reactors produce large amounts of long-lived radioactivity. If this high level waste is not properly disposed or if there is much processing of this waste environmental contamination may result. A typical 1000 megawatt year reactor may produce 27.5 kilograms ( 467 curies) of technetium-99 $\left({ }^{99} \mathrm{Tc}\right.$ ) (Del Cul, et al. 1993). Wildung (Wildung, et al. 1979) estimated that by the year 2000 , the United States will have in excess of $1.7 \times 10^{5}$ kilograms or $2.86 \times 10^{6}$ curies of ${ }^{99} \mathrm{Tc}$ in inventory. Apparently, some technetium-99 has contaminated our environment as evidenced by analysis of soil samples from a number of sites.

Uranium-238 $\left({ }^{238} \mathrm{U}\right)$, in the form of pitchblende (about $\left.50 \% \mathrm{U}\right)$, was found to contain $2.5-3.1 \times 10^{-10}$ grams of ${ }^{99} \mathrm{Tc}$ per kilogram of ore. The technetium-99 was believed to be produced by a spontaneous fission process (Kenna and Kuroda, 1964). Neutron induced fission of ${ }^{235} \mathrm{U}$ by cosmic ray neutrons occurs in nature 
(Kenna and Kuroda, 1960), producing more ${ }^{99} \mathrm{Tc}$ than from the spontaneous fission of ${ }^{238} \mathrm{U}$.

Technetium-99 may find its way into the environment through the use of ${ }^{99 \mathrm{~m}} \mathrm{Tc}$ in nuclear medicine. In the United States in 1978 about six million nuclear medicine procedures were performed with about $90 \%$ of them using ${ }^{99 m} T c$ (Richards, et al. 1982). There is no control nor collection of excreta from patients undergoing such procedures. Furthermore, because there are no low-level radioactive waste repositories, many hospitals hold their low level waste generated by technetium $-99 \mathrm{~m}$ procedures until the activity decays $\left({ }^{99 \mathrm{~m} T c}, \mathrm{~T}^{\mathrm{T}} \mathrm{2}=6\right.$ hours $)$. It is then released as non-radioactive waste. If one calculates the amount of ${ }^{99} \mathrm{Tc}$ released from the above nuclear medicine procedures throughout the U.S., assuming about 30 millicuries per procedure, about 31 milligrams or 0.52 millicuries of ${ }^{99} \mathrm{Tc}$ are introduced into the environment each year (see Appendix I).

Although these are small numbers, over many years and increased use of ${ }^{99 m} \mathrm{Tc}$, this may be cause for concern. It is essential to realize that the advantages to the general population, through the use of such nuclear medicine procedures, far outweigh the relatively minor insult to the environment by the introduction of ${ }^{99 \mathrm{~m} T c}$. If controls could be easily adapted for such use of ${ }^{99 \mathrm{~m}} \mathrm{Tc}$, this impact could be minimized.

There have been spectroscopic observations of $\mathrm{Tc}(\mathrm{l})$ lines in various $\mathrm{S}$ and $\mathrm{N}$ type stars (Kenna, 1962). Some of these reports are the subject of debate. If this is so, the process is not completely understood; however, it was suggested that neutrinos may have played a role in the production of technetium. 
This investigation was undertaken to address the behavior of technetium in the Brookhaven National Laboratory (BNL) Citric Acid Process developed at BNL by Francis and Dodge (Francis, Dodge, 1994), for the removal of radionuclides from contaminated soil. In this process, citric acid is used to form soluble metal citrate complexes which are subsequently subjected to degradation by Pseudomonas fluorescens, bacteria. Uranium citrate does not degrade under these conditions, but upon photolysis degrades to uranium trioxide. The metals may then be reclaimed without producing additional waste to be disposed.

This work reviews the literature concerning the behavior of technetium in various types of soils. The real key to understanding how an element behaves in the environment is to thoroughly understand its chemistry. Since technetium is used in nuclear medicine, its chemistry has been well studied and that data will be reviewed. Technetium normally exists as an anion. One would expect it to move with the groundwater flow unless it gets reduced or anionically bound to soil. The investigative portion of this work addresses the methods for the recovery and detection of technetium- 99 in four soils from two actual sites. The use of gamma emitting ${ }^{99 m} T c$ greatly facilitated the recovery and methods development. Technetium-95m was used to determine its behavior in the BNL Citric Acid Process in an effort to develop a remediation process.

Based on the behavior of technetium-99 in the soils studied, a theory was postulated as to how it may have been deposited there. 
Chapter 2

\section{Literature Review}

Technetium, atomic number 43 , is a synthetic element first reported by Perrier and Segrè in 1937 (Boyd, 1959). It was first produced by the transmutation of molybdenum by bombardment with protons or deuterons in the Berkeley cyclotron. There are seventeen known isotopes of technetium. The two of greatest interest are technetium-99m $\left({ }^{99 \mathrm{~m} T c}\right)$ with a half-life $\left(\mathrm{T}^{1 / 2}\right)$ of six hours and ${ }^{99} \mathrm{Tc}\left(\mathrm{T}^{1 / 2}=2.13 \times 10^{5}\right.$ years $)$. Seaborg and Segrè first studied ${ }^{99 \mathrm{~m}} \mathrm{Tc}$, the isotope widely used in nuclear medicine procedures. Long-lived ${ }^{99} \mathrm{Tc}$ was first isolated in 1946 from fission products and long irradiation of molybdenum metal.

Extensive use of ${ }^{99 \mathrm{~m}} \mathrm{Tc}$ in nuclear medicine was largely due to the development of a ${ }^{99 \mathrm{~m}} \mathrm{Tc}$ generator developed at Brookhaven National Laboratory by Tucker and Greene (Richards, 1982). The generator consisted of ${ }^{99} \mathrm{Mo}$ loaded onto an alumina column. Molybdenum-99 decays with a $T 1 / 2$ of 66 hours to ${ }^{99 m} T c$ and ${ }^{99}$ Tc. Technetium-99m can be "milked" off the column by simply washing a saline solution through the column. The development of a technetium generator made technetium readily available to hospitals. One generator could provide technetium$99 \mathrm{~m}$ on a daily basis for at least one week. Because of the interest of technetium in the nuclear medicine community and the availability of ${ }^{99} \mathrm{Tc}$, numerous chemical studies were undertaken by our Radionuclide/Radiopharmaceutical Development Group at Brookhaven National Laboratory (Eckelman, et al. 1971, 1972 and Steigman et al. $1974,1975,1978$ ) in an effort to understand the chemistry involved in making radiopharmaceuticals with the intent of improving the quality. 
Nuclear medicine is a medical specialty that uses the nuclear properties of radioactive nuclides to evaluate metabolic, physiologic and pathologic conditions of the body. Typically, a patient is administered radioactive material, either by inhalation, intravenous or oral means and imaged under a gamma camera after a suitable circulation time. As the radioactive material decays, it releases photons of energy that are detected and recorded on film and or computer. The amount of radiation exposure is generally less than that received by an $x$-ray procedure. Technetium- $99 \mathrm{~m}$ is an ideal isotope for nuclear medicine procedures in that it has a relatively short half-life, and an easily detectable 140 kiloelectron volt photon. This photon is energetic enough to be detected but low enough to produce minimal radiation exposure.

Because technetium-99m is used in nuclear medicine, the biological half-life of technetium in its normal oxidized form and in the form of many radiopharmaceuticals has been well studied. The biological half-life of technetium pertechnetate $\left(\mathrm{Na}^{99 \mathrm{~m}} \mathrm{TCO} 4\right)$ was reported by a task group lead by Lathrop (Lathrop et al. 1976). Within twenty-four hours just about all the technetium clears an animal's system. This information is very valuable in the event that ${ }^{99} \mathrm{Tc}$ is taken internally.

Technetium normally exists as an anion of sodium or potassium, called sodium pertechnetate $\left(\mathrm{NaTcO}_{4}\right)$. Its normal oxidation state is +7 . Rhenium behaves very similarly to technetium and is often used as a carrier or analog. Sometimes it is used to develop technetium chemistry without the precautions necessary for working with radioactive material. Rhenium does have different 
redox potentials, so it is necessary to realize the limitations for comparison with technetium. Usually it is necessary to reduce technetium to lower oxidation states in order to complex it to various ligands (complexing molecules). In many of the radiopharmaceuticals studied (Eckelman et al. 1971, 1972 and Steigman et al. $1974,1975,1978)$, the predominant oxidation states are 3,4 and 5 . Complexes of technetium in the $+2,+1,0$ states have been prepared (Steigman and Eckelman, 1992), but are generally difficult to prepare organic molecules, that would not be normally encountered in the environment.

Technetium can get reduced easily and oxidized easily. However, if there is not a large excess of complexing agent present when technetium gets reduced, it will tend to hydrolyze. Reduced hydrolyzed technetium is not very soluble and tends to "stick" to whatever is present. This hydrolysis problem causes great difficulty when trying to produce crystals of complexes for characterization by $x$ ray. Muenze (Muenze 1981) got a glassy material when attempting to grow technetium (IV)-citrate crystals. Technetium in the +5 oxidation state as $\left(\mathrm{TcOCl}_{5}\right)^{-2}$ can disproportionate into $\mathrm{TCO}_{2}$ (hydrolyzed $\mathrm{Tc}$ ) and $\mathrm{TcO}_{4}$. Various chemicals such as stannous tin, borohydride, dithionite, ascorbic acid, hydrazine, hydrochloric acid are just some of the agents used (Steigman and Eckelman, 1992) in the reduction of technetium. If reducing agents such a stannous tin or ferrous iron are complexed, they may have still a different redox potential. For example the $\mathrm{Fe}^{+2} / \mathrm{Fe}^{+3}$ redox couple is 0.771 volts versus the standard hydrogen electrode, but when complexed to ethylenediamine tetraacetic acid (EDTA) the potential is 0.12 volts (Eckelman, et al. 1971). 
Technetium can be volatile, reportedly, it can be distilled from sulfuric or perchloric acid (Boyd, G.E. 1959).

Technetium as pertechnetate $\left(\mathrm{TCO}_{4}{ }^{-}\right)$has a characteristic absorption spectra (Figure 1), with absorption at 2440 and 2875 angstroms and a molar absorptivity of 6220 and $2360 \mathrm{~cm}^{-1} \mathrm{M}^{-1}$, respectively. Hexachlorotechnetate $\left(\mathrm{TcCl}_{6}\right)^{-2}$, technetium in the +4 oxidation state, has a characteristic spectra (Figure 2) with bands at 2400 and 3380 angstroms. The molar absorptivity at $2400 \AA$ is about $11000 \mathrm{~cm}^{-1} \mathrm{M}^{-1}$ (Boyd, G.E. 1959).

Technetium in the +7 oxidation state is readily extracted from $2.5 \underline{N}$ sodium hydroxide with methyl ethyl ketone (MEK). Reduced technetium has been extracted by first forming a well-defined neutral technetium complex by substitution reactions to produce water insoluble complexes (Steigman and Eckelman 1992). Because these extractions are performed in air, oxidation of technetium to the +7 state is always a problem if one is attempting to determine its oxidation state in that complex.

A search of the literature on the analytical chemistry of technetium shows that technetium forms a number of colored complexes that give a sensitivity of detection in the order of 0.02-0.06 micrograms (Feigl and Anger 1972). In all these methods technetium is in the reduced state. Crouthamel (Crouthamel 1957) published an analytical procedure using thiocyanate which produces a technetium complex with a molar absorptivity $(\varepsilon)$ of $52,200 \mathrm{~cm}^{-1} \mathrm{M}^{-1}$. The $1,5-$ diphenylcarbohydrazide complex of technetium has a $€$ of 48,600 (Miller and Zittel (1963). Neutron activation analysis of ${ }^{99} \mathrm{Tc},\left[{ }^{99} \mathrm{Tc}(\mathrm{n}, \mathrm{y})^{100} \mathrm{Tc}\right]$ produces ${ }^{100} \mathrm{Tc}$ with a 


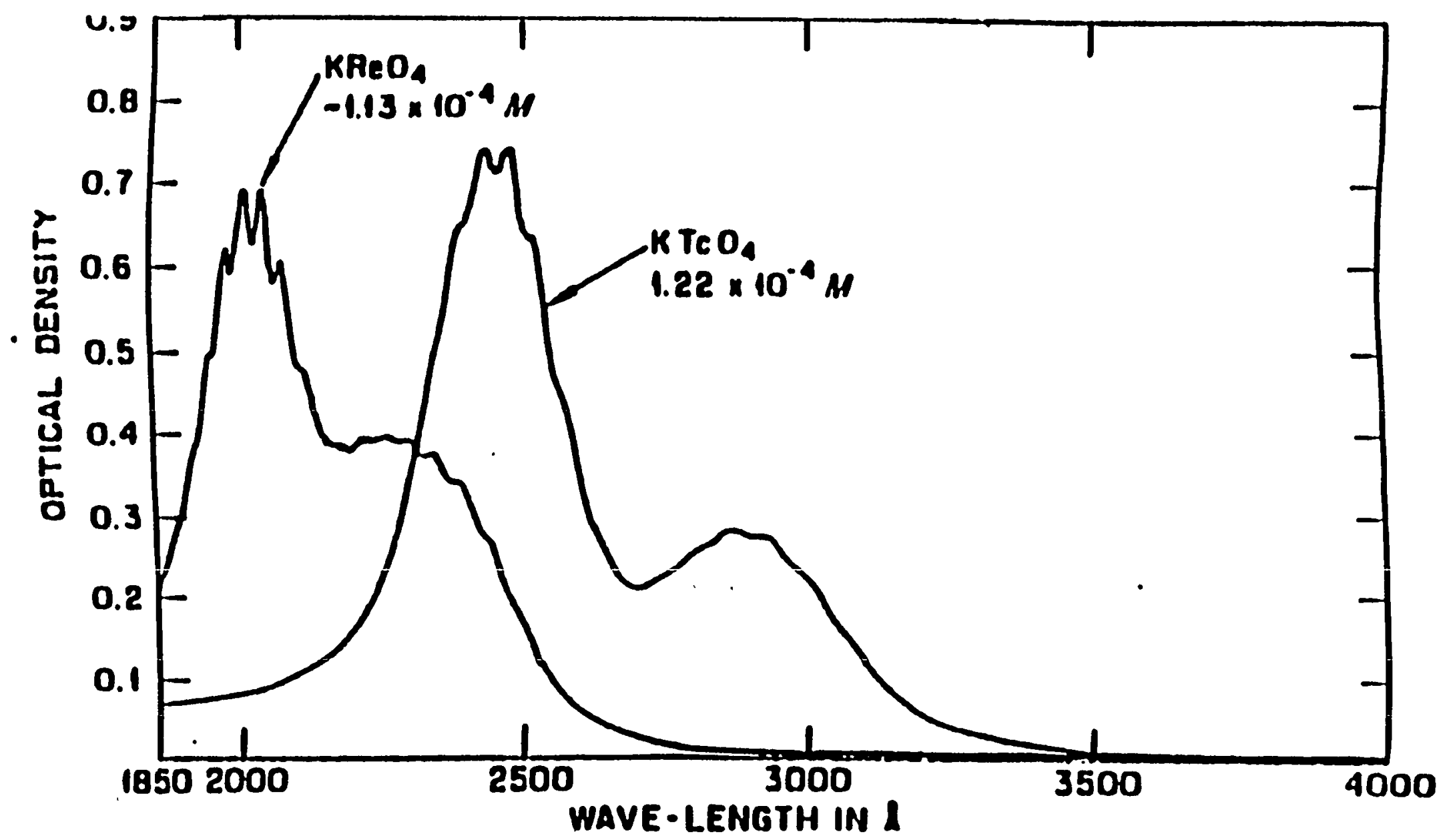

Figure 1: Absorption Spectra of Perrhenate and Pertechnetate $\left(\mathrm{TcO}_{4}^{-}\right)$ [Boyd, 1962] 


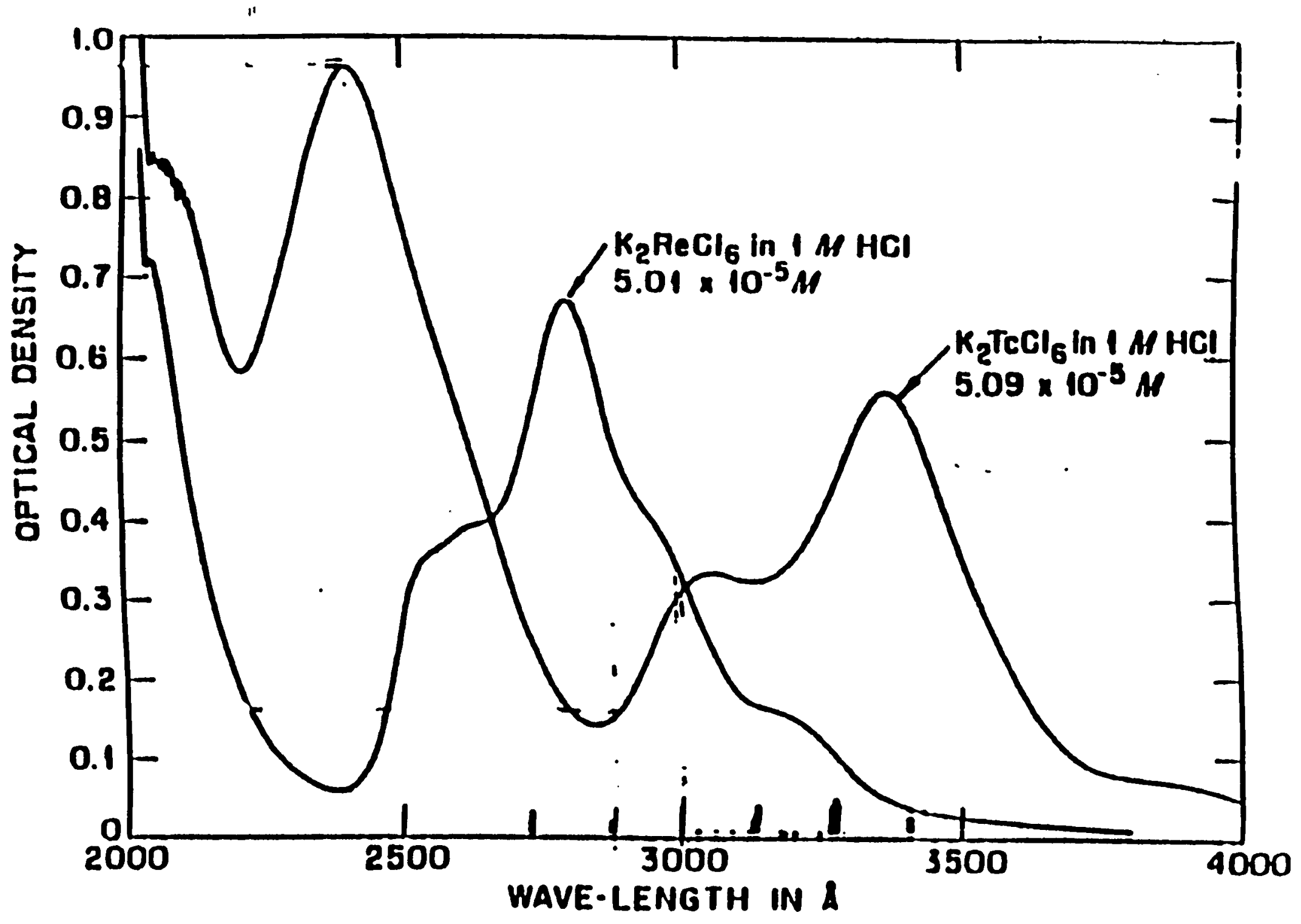

Figure 2: Absorption Spectra of Hexachlororhenate and hexachlorotechnetate $\left(\mathrm{TcCl}_{6}\right)^{-2}$ [Boyd, 1962] 
half-life of 15.8 seconds (Foti et al. 1972) with a sensitivity of detection of $2 \times 10^{-11}$ grams. With such a short half-life, activation analysis is extremely difficult to practically perform and analyze.

The most sensitive means for measuring low levels of ${ }^{99} \mathrm{Tc}$ is by beta counting using gas proportional or liquid scintillation counting. When a radioactive material decays, it releases energy, so the response of atom amounts of material is measured. This is far more sensitive than colorimetric methods. Technetium -99 is a beta emitter, releasing a beta particle of $293 \mathrm{KeV}$. Beta particles may be detected by placing the radioactive material in a scintillant, usually an organic liquid, that absorbs the energy and produces a light response which is quantified.

In Gabon, Africa, there are the remains of naturally occurring fission products produced form uranium rich zones beginning nuclear fission $2 \times 10^{9}$ years ago and remaining critical for several hundred thousand years (Gancarz et al. 1980). Technetium-99 decays to stable ruthenium-99 $\left({ }^{99} \mathrm{Ru}\right)$; the nuclear fission produces ${ }^{101} \mathrm{Ru},{ }^{102} \mathrm{Ru},{ }^{104} \mathrm{Ru}$ instantaneously. That is, the precursors to ${ }^{101,102,104} \mathrm{Ru}$ are shortlived relative to the rate of geologic processes. The rate of production of ${ }^{99} \mathrm{Ru}$ is much slower than for the other fissiongenic Ru isotopes because of the long ${ }^{99} \mathrm{TC}$ half-life. Fractionation of ${ }^{99} \mathrm{Ru}$ and ${ }^{99} \mathrm{Tc}$ can produce measurable differences in the ratio, ${ }^{99} \mathrm{Ru} /{ }^{101} \mathrm{Ru}+{ }^{102} \mathrm{Ru}$. These authors measured such ratios and found differences. They suggested that this fractionation may be due to a number of environmental conditions. One was that uranium cleposits are considered to be strongly reducing environments (Curtis 1986) thereby reducing technetium and making it immobile. Another condition has to do with geologic conditions being 
unstable thereby redistributing the ${ }^{99} \mathrm{Tc}$. Temperature increases, between $100^{\circ}$ and $200^{\circ} \mathrm{C}$, produced by the reactors can also explain the many differences. Radiation effects producing different redox environments result in iron equally divided between the oxidized and reduced forms. Such conditions could reduce or oxidize ${ }^{99} \mathrm{Tc}$ causing a redistribution.

Strickert et al. (Strickert et al. 1979) studied the absorption of technetium and iodine by naturally occurring minerals (bournonite, chalcopyrite, pyrite, tennantite and tetrahedrite). They used columns of crushed minerals and batch techniques contacted with solutions of pertechnetate-95m and iodine $\left(\mathrm{I}^{-}\right)$and $\left(\mathrm{IO}_{3}^{-}\right)$ as iodine-131. They found technetium absorption to minerals containing copper, lead or iron in their reduced oxidation states. That is oxidation-reduction is involved in the absorption process - not ion exchange. The authors tabulated distribution coefficients $\left(K_{D}\right)$ for various minerals for ${ }^{95 \mathrm{~m}} \mathrm{TcO}_{4},{ }^{131} \mathrm{l}$, and ${ }^{131} \mathrm{IO}_{3}^{-}$.

It has been shown that igneous rocks under anaerobic conditions have the ability to reduce technetium-99 (Bondietti, Francis 1979). The authors measured oxidation-reduction potentials with igneous rock or shale. Under oxidizing conditions technetium was not reduced. They point out that other tetravalent actinides show limited solubility in nature. Also major uranium deposits occur in reducing environments as a result of the reduction of $U(V I)$ to insoluble $U(I V)$. The authors indicate that the reactivity of the rocks, the geologic contact time and the degree of fracturing are factors that influence the chemical state of the migrating elements. 
Palmer and Meyer (Palmer, Meyer 1981), studied the ion-exchange capacity of various minerals for pertechnetate at various sodium chloride concentrations and $\mathrm{pH}$ ranges. They tabulated distribution coefficients and demonstrated that pertechnetate could be retained by minerals by an ion-exchange mechanism.

A study of eleven soils, well characterized by physical and chemical properties suggested that high organic content and/or microbial activity may be responsible for pertechnetate absorption (Landa et al. 1977). They found that three to five weeks were required for sorption to occur. When they added dithionite to soils to complex iron oxides, they reduced sorption. Soils that were first sterilized eliminated ${ }^{99} \mathrm{Tc}$ sorption, suggesting that microbes may reduce and immobilize technetium.

There are studies indicating that soybeans and wheat readily take up the pertechnetate ion (Wildung et al. 1979). Plants grown in soils greater than $0.1 \mu \mathrm{g}$ ${ }^{99} \mathrm{Tc}$ per gram soil showed toxicity of a biochemical nature. Marine algae concentrated technetium greater than $10^{4}$ times (Birks 1975). These observations suggest interesting future studies. For example, it might be interesting to analyze fish caught in waters close to hospitals. In this type of study, it would be necessary to determine if sanitary waste is being released to that body of water. In larger animals such as mice, dogs and humans, the biological half-life is rapid as has been previously described.

Researchers have shown that aged precipitates of ferrous sulfide could take up $90 \%$ of the added pertechnetate in five days (Lee, Bondietti 1983). Over long time periods ferrous sulfide recrystallized by dissociation and oxidation to hermatite 
releasing some technetium. In other iron precipitates where they did not recrystallize, the technetium remained with the precipitate. This study suggests reduction of technetium by ferrous iron and perhaps release of technetium upon recrystallization of the precipitate.

There are indications that technetium pertechentate was reduced during the growth phase of Morarella and Planococcus spp. (Pignolet et al. 1989). Desulfovibrio gigas and $D$. vulgaris, sulfate-reducing microorganisms, have been shown to reduce pertechnetate to an insoluble (reduced) form (Henrot 1989). 


\section{Chapter 3}

Investigative Procedure

The basic objectives of the study were: 1 ) to determine ${ }^{99} \mathrm{Tc}$ concentrations in soils, optimizing extraction methods and concentration schemes. 2) to determine behavior of technetium in citric acid toxic metal extraction procedure 3) determine speciation of ${ }^{99} \mathrm{Tc}$ in soil. 4) characterize ${ }^{99} \mathrm{Tc}$ citrate and method of formation for use in bioremediation process.

The multitude of equipment, reagents radioisotopes and soil samples used as part of these investigations are summarized below.

\section{Equipment:}

Shimadzu UV 260 Spectrophotometer

Beckman LS7800 liquid scintillation counter

Canberra Series 85 multichannel analyzer (MCA) with Spectran-F analysis program LKB/Wallac gamma counter

Atomlab 100 dose calibrator

Sorvall RC 2-B Superspeed centrifuge

International Equipment Company IEC Centra-7R centrifuge

Burrell wrist action shaker

Brinkman rotary evaporator

Rainin electronic pipets

Fischer Scientific Company U.S. Standard Sieve series

\section{Reagents:}

Pharmacia G-25 Sephadex gel 
Chemicals, ACS reagent grade

Rhodium foil, 99.8\% Aesar (Johnson Matthey)

Packard Ultima gold XR environmentally safe liquid scintillant

Technetium-99 NIST std from Amersham International

\section{Radioisotopes:}

$\mathrm{NH}_{4}{ }^{99} \mathrm{TcO}_{4}$, Oak Ridge National Laboratory, 43 milligrams per $\mathrm{ml}$ $\mathrm{Na}{ }^{99 m} \mathrm{TcO}_{4}$, Syncor, Garden City supplied from a DuPont generator $\mathrm{Na}{ }^{95 \mathrm{~m}} \mathrm{TCO}_{4}$ Brookhaven Linac Isotope Producer (BLIP) irradiation of rhodium

Soils:

Parsons RMI project, Ashtabula, $\mathrm{OH}$

samples $27117,27227,27230$

Fermco 402585

\subsection{Production of Technetium 95m:}

A one inch square piece of 0.010 inch thick rhodium foil $99.8 \%$ pure was irradiated in the Brookhaven Linac Isotope Producer (BLIP) using 200 MEV (million electron volt) protons. The BLIP uses a bending magnet to take a portion of the proton beam from the Linear accelerator (LINAC); the remainder of the beam goes to the Alternating Gradient Synchrotron (AGS) for high energy physics research. The target was irradiated for 68 days with a total current of 54596.6 microamperes. Technetium- $95 \mathrm{~m}$ was processed from the rhodium target by dissolution of the rhodium foil using A.C. electrolysis in six molar hydrochloric acid. The dissolved rhodium foil in hydrochloric acid was made five normal overall in sodium hydroxide and extracted with methyl ethyl ketone (Boyd, Larson 1959). 
The above irradiation produced 14 millicuries of ${ }^{95 \mathrm{~m}} \mathrm{Tc}$. The nuclear reaction is ${ }^{103} \mathrm{Rh}$ $(p, 3 p, 6 n)^{95 m}$ Tc. Appendix IV lists other technetium isotopes produced in the irradiation.

Table 1.

Technetium Isotopes Used and Physical Characteristics

$\begin{array}{llcl}\text { Isotope } & \text { Emission } & \text { Primary energy }(\mathrm{KeV}) & \text { Half-life }\left(\mathrm{T}^{1} \mathrm{2}\right) \\ { }^{99} \mathrm{Tc} & \text { beta particle } & 293 & 2.13 \times 10^{5} \mathrm{yrs} \\ { }^{95 \mathrm{~m} T c} & \text { gamma } & 204,582 & 61 \text { days } \\ { }^{99 \mathrm{~m} T \mathrm{Tc}} & \text { gamma } & 140 & 6 \text { hours }\end{array}$

3.2 Characterization and Formation of Technetium Citrate at $\mathrm{pH} 3$ and $\mathrm{pH} 6$

The objective of this aspect of the study was to prepare technetium citrate without metal reducing agents for possible future use in bioremediation studies. Technetium citrate forms a complex fairly easily in a stannous citrate environment (Steigman 1975). The presence of other metals may complicate the study; so a means to make ${ }^{99} \mathrm{Tc}$-citrate without metals was designed.

3.2.1 Reduction of pertechnetate $\left({ }^{99} \mathrm{TcO}_{4}{ }^{-}\right)$to hexachloro technetate $\left(\mathrm{TcCl}_{6}\right)^{-2}$ : 
Twenty microliters of 41.7 milligrams per milliliter of $\mathrm{NH}_{4}{ }^{99} \mathrm{TcO}_{4}$ was added to a round bottom flask along with 15 microliters of ${ }^{95 \mathrm{~m}} \mathrm{TcO}_{4}^{-}(42 \mu \mathrm{ci})$ and $0.1 \mathrm{ml} 17$ $\mathrm{mg} / \mathrm{ml}$ potassium iodide in $0.1 \underline{\mathrm{N} \mathrm{NaOH}}$ and $3 \mathrm{mls}$ of concentrated hydrochloric acid. The flask was assembled with an air cooled condenser venting to a dry ice cooled trap in a well-vented and HEPA (high efficiency particulate air) filtered hood. Technetium can become volatile and great care must be used to prevent contamination. The reaction was heated at $105^{\circ} \mathrm{C}$ overnight using an oil bath on a hotplate to provide uniform heating. An added stir bar provided good mixing. After heating overnight the solution appeared yellow in color and no crystals were present. An aliquot of $0.2 \mathrm{ml}$ was diluted to $3 \mathrm{ml}$ with $6 \mathrm{M} \mathrm{HCl}$ and the spectrum . measured which is shown in Figure 3. Calculation of the concentration of ${ }^{99} \mathrm{Tc}$ and comparison of absorbance based on a molar absorptivity (e) of 11000 for hexachlorotechnetate, indicated that all the technetium had gotten reduced. After aliquots were taken for complexation with citrate, the remainder of the $\mathrm{HCl} / \mathrm{KI}^{99} \mathrm{Tc}$ was heated. No further change in spectrum was observed indicating that all the ${ }^{99} \mathrm{TcO}_{4}^{-}$had gotten reduced to $\mathrm{TcCl}_{6}^{-2}$.

\subsubsection{Complexation experiments with citrate:}

Aliquots of reduced technetium by the $\mathrm{HCl} / \mathrm{KI}$ process were added to $10,30,90,300$ fold molar excesses of citrate at $\mathrm{pH} 3$ and incubated at $37^{\circ} \mathrm{C}$ for various times (15 $\mathrm{min}, 13 \mathrm{hr}$ ) under a nitrogen covergas. The spectrum was remeasured (Figure 4) and aliquots were analyzed on a $0.9 \times 35 \mathrm{~cm} \mathrm{G-25} \mathrm{M}$ Sephadex column eluted with a pH 3 citrate buffer. Previous calibration of the Sephadex columns indicate ${ }^{99} \mathrm{Tc}$ citrate has a peak elution volume of $20 \mathrm{ml}, 1$ 


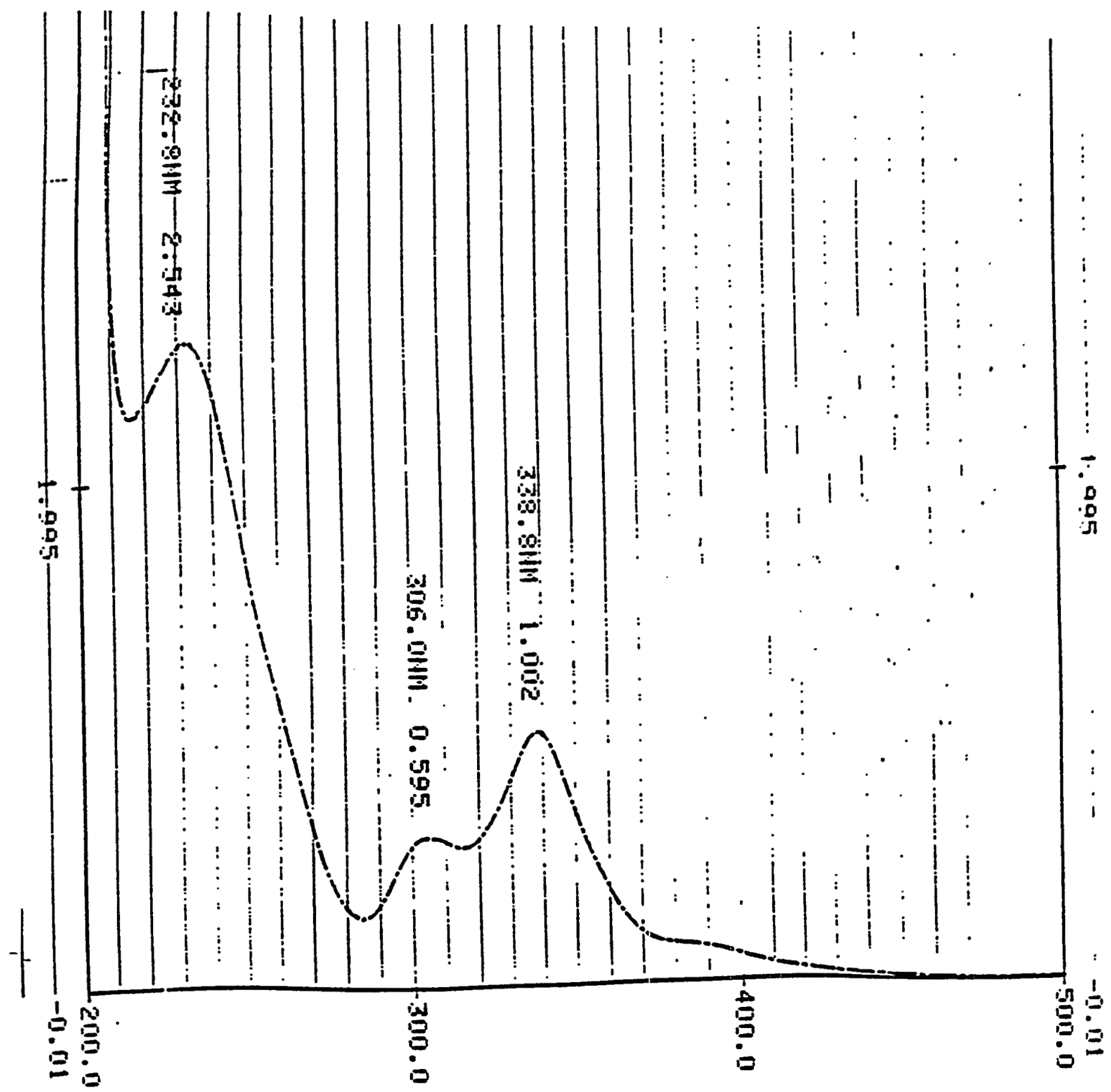

Figure 3. Hexachlorotechnetate $\left(2.05 \times 10^{-4} \mathrm{M} \mathrm{TCCl}_{2}\right)^{-2}$ in $2 \mathrm{M} \mathrm{HCl}$ Reduced in $\mathrm{HCl} / \mathrm{KI}$ 


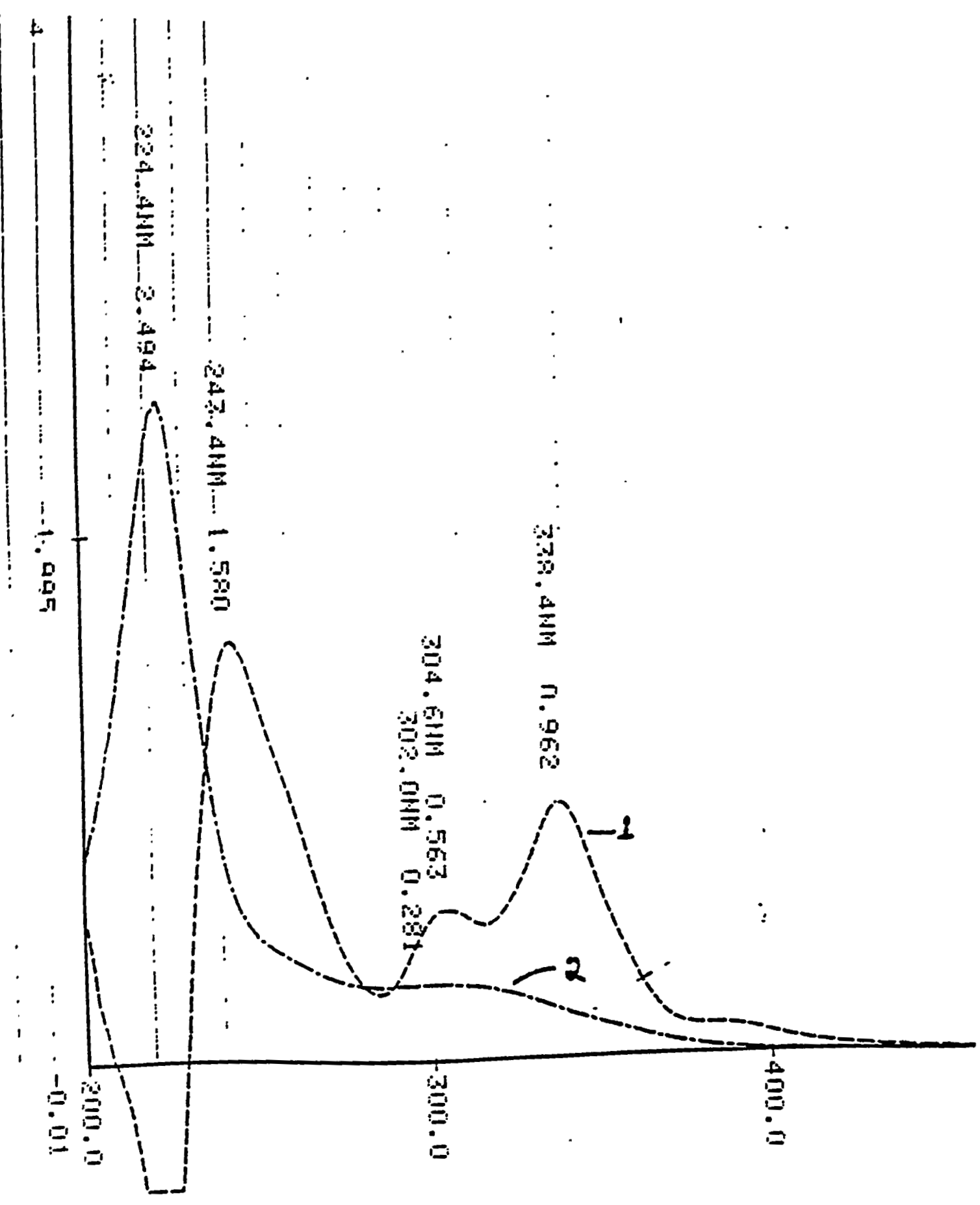

Figure 4. (1) and 100 fold (2) Molar Excess of Citrate pH 3, 24 hours at $37^{\circ} \mathrm{C}$. 
column volume is $30 \mathrm{ml}$ and void volume $10-12 \mathrm{ml}$. Pertechnetate has an elution volume of $40 \mathrm{ml}$ and, hexachlorotechnetate $34 \mathrm{ml}$. Sephadex is a gel that separates on the basis of molecular size but also has some ion exchange behavior. Sephadex G-25 $M$ has a fractionation range of $1000-5000$ daltons for peptides and globular proteins and $100-5000$ for dextrans. Gel filtration media separates by allowing small molecules to enter pores, big molecules can not fit and get excluded from the pores and travel around the bead and get excluded. One can envision a glass bead with a small hole in it. Small molecules travel a tortuous path and are retained, large molecules travel around the bead and are eluted first. In the analysis of these samples by Sephadex, an aliquot was taken for counting and compared to all fractions. The same size aliquot was placed on the column. Uniform fractions of known volume were collected and counted in a gamma counter and compared to the counting standard. The percentage of activity associated with each complex and the total activity recovered was determined. $A_{1}$ loss of activity on the column suggests hydrolysis of technetium. This hydrolyzed technetium may be removed by washing the column with a dilute solution of hydrogen peroxide and collecting and counting for quantification.

The above experiments demonstrated that at $\mathrm{pH} 3$ it was necessary to have at least a $100-300$ fold molar excess of citrate at $37^{\circ} \mathrm{C}$ overnight to produce on $80 \%$ yield of complex. At pH 3 the citrate apparently does not readily displace the chlorides of $\left(\mathrm{TcCl}_{6}\right)^{-2}$. The yield of technetium-citrate at $\mathrm{pH} 6$ was compared to $\mathrm{pH}$ 3 at the same concentrations and reaction conditions. 
At pH 6 in 30 minutes $81 \%{ }^{95 m / 99} \mathrm{Tc}$-citrate was produced compared to $4 \%$ at $\mathrm{pH}$ 3. Technetium citrate prepared by using stannous citrate was evaluated for comparison. Stannous is a more efficient reducing agent and this system has been studied. A 5 fold molar excess of stannous over technetium concentration was added with a 12.8:1 citrate: tin molar ratio and a 128:1 citrate: technetium molar ratio with citrate at $\mathrm{pH} 3$ and $\mathrm{pH} 6$. At 30 minutes at $37^{\circ} \mathrm{C}$ at $\mathrm{pH} 3$ and $\mathrm{pH} 6$ $100 \%$ of the technetium was complexed to the citrate. In the $\mathrm{HCL} / \mathrm{KI}$ reduction with citrate complexation, the citrate: technetium molar ratio was about 2000:1. The absorption spectra of technetium citrate reduced by stannous does not show any peaks, only strong absorption at $220-200 \mathrm{~nm}$. To summarize the above experiments, technetium can get reduced to $\left(\mathrm{TcCl}_{6}\right)^{-2}$ in $\mathrm{HCl} / \mathrm{KI}$ and is stable for long periods of time with the exclusion of air (weeks) when stored in the HCL/KI. A ${ }^{99} \mathrm{Tc}$-citrate complex can be formed from the $\mathrm{HCl} / \mathrm{KI}$ reduction of ${ }^{99} \mathrm{TCO}_{4}^{-}$, but a large excess of citrate is necessary. A pH of 6 allows for easier substitution of citrate for the chlorides of hexachlorotechnetate. Reduced technetium hexachlorotechnetate does not hydrolyze in $\mathrm{pH} 3$ citrate as evidenced from absorption spectra. Stannous tin is a much more effective means for reduction and complexation of technetium to citrate. Table 2 summarizes the sephadex results for technetium citrate yields by stannous citrate and $\mathrm{HCl} / \mathrm{KI}$ reduction. Muenze (Muenze 1981) tried to isolate technetium citrate crystals for $\mathrm{x}$-ray diffraction characterization and got a glassy mass. This demonstrates how technetium will hydrolyze without a large excess of ligand. 


\section{Table2}

Technetium Citrate Yields Produced by Reduction with

Stannous or $\mathrm{HCl} / \mathrm{KI}$ Determined by the Use of Sephadex

\begin{tabular}{||c|c|c|c|c||}
\hline \multicolumn{4}{|c|}{ Stannous Citrate } \\
\hline \hline citrate fraction & $100 \%$ & $100 \%$ & $100 \%$ & $100 \%$ \\
\hline $\mathrm{TcCl}_{6}^{-2}$ fraction & $\cdots$ & $\cdots$ & $\cdots$ & $\cdots$ \\
\hline $\begin{array}{c}\mathrm{TcO}_{4}^{-} \text {fraction \% } \\
\text { recovered }\end{array}$ & 100 & 100 & 100 & 100 \\
\hline
\end{tabular}

\begin{tabular}{||c|c|c|c|c||}
\hline \multicolumn{4}{|c}{30 minutes @ $37^{\circ} \mathrm{C}$} & \multicolumn{2}{c|}{$0 . \mathrm{N} \mathrm{@} 37^{\circ} \mathrm{C}$} \\
\hline \hline & $\mathrm{pH} \mathrm{3}$ & $\mathrm{pH} \mathrm{6}$ & $\mathrm{pH} \mathrm{3}$ & $\mathrm{pH} \mathrm{6}$ \\
\hline citrate fraction & $4 \%$ & $81 \%$ & 88 & 86 \\
\hline $\begin{array}{c}\mathrm{TcCl}_{6}^{-2} \\
\text { fraction }\end{array}$ & 88 & 4 & -- & - \\
\hline $\mathrm{TcO}_{4}{ }^{-}$fraction & -- & -- & -- & 11 \\
\hline$\%$ recovered & 92 & 85 & 88 & 97 \\
\hline
\end{tabular}

\subsection{Soil characterization:}

Grain size, moisture and amount of organic material was determined to characterize the soils studied. Soils were air-dried for four days then sieved through a $2 \mathrm{~mm}$ sieve. All material less than $2 \mathrm{~mm}$ was analyzed for technetium and other metals. Approximately $35-40 \%$ of the soils were greater than $2 \mathrm{~mm}$. 
The grain size distribution of less than $2 \mathrm{~mm}$ soils was determined by sieving through a series of U.S. standard sieve series. Fifty gram samples were sieved and various grain sizes collected, weighed and represented as a fraction of the total. A plot on semilogarithmic paper of grain size in millimeters versus percentage finer than was plotted (Fig 5). The uniformity coefficient and effective grain size was tabulated. The data was compared to Table 3, Soil Classification Based on Particle Size (Todd 1976) and the triangle of soil textures (Fig 6) for describing various combinations of sand, silt, and clay (Soil Survey Staff). The soils were found to be of a sandy nature. Table 4 lists the effective grain size $\left(d_{10}\right)$, the uniformity coefficient $\left(U_{c}=d_{60} / d_{10}\right)$, the moisture content and the weight loss on ashing at $500 \mathrm{C}$ and the soil $\mathrm{pH}$.

The effective grain size is a parameter that is useful for determining the hydraulic conductivity of soils (Todd 1976). Hydraulic conductivity is a measure of the transmission of a unit volume of water through a medium of unit cross sectional area. A soil with a low uniformity coefficient is relatively uniform (a steep particle size distribution graph). A well graded soil has a high uniformity coefficient (less steep particle size distribution curve).

The $\mathrm{pH}$ of the soils were determined by adding 5 milliliters of water of 5 grams of soil with vortex mixing. The soil was centrifuged and $\mathrm{pH}$ of water layer measured. 


\begin{tabular}{ccccc}
\multicolumn{5}{c}{ \% finer than } \\
$\mathrm{mm}$ & $\# 1$ & $\# 2$ & $\# 3$ & $\# 4$ \\
1.19 & 44.25 & 60.31 & 74.84 & 60.35 \\
0.59 & 17.13 & 29.89 & 48.31 & 32.08 \\
0.5 & 13.01 & 23.87 & 41.01 & 25.91 \\
0.15 & 4.26 & 9.02 & 14.13 & 9.53 \\
0.074 & 1.93 & 4.34 & 5.79 & 5.19
\end{tabular}

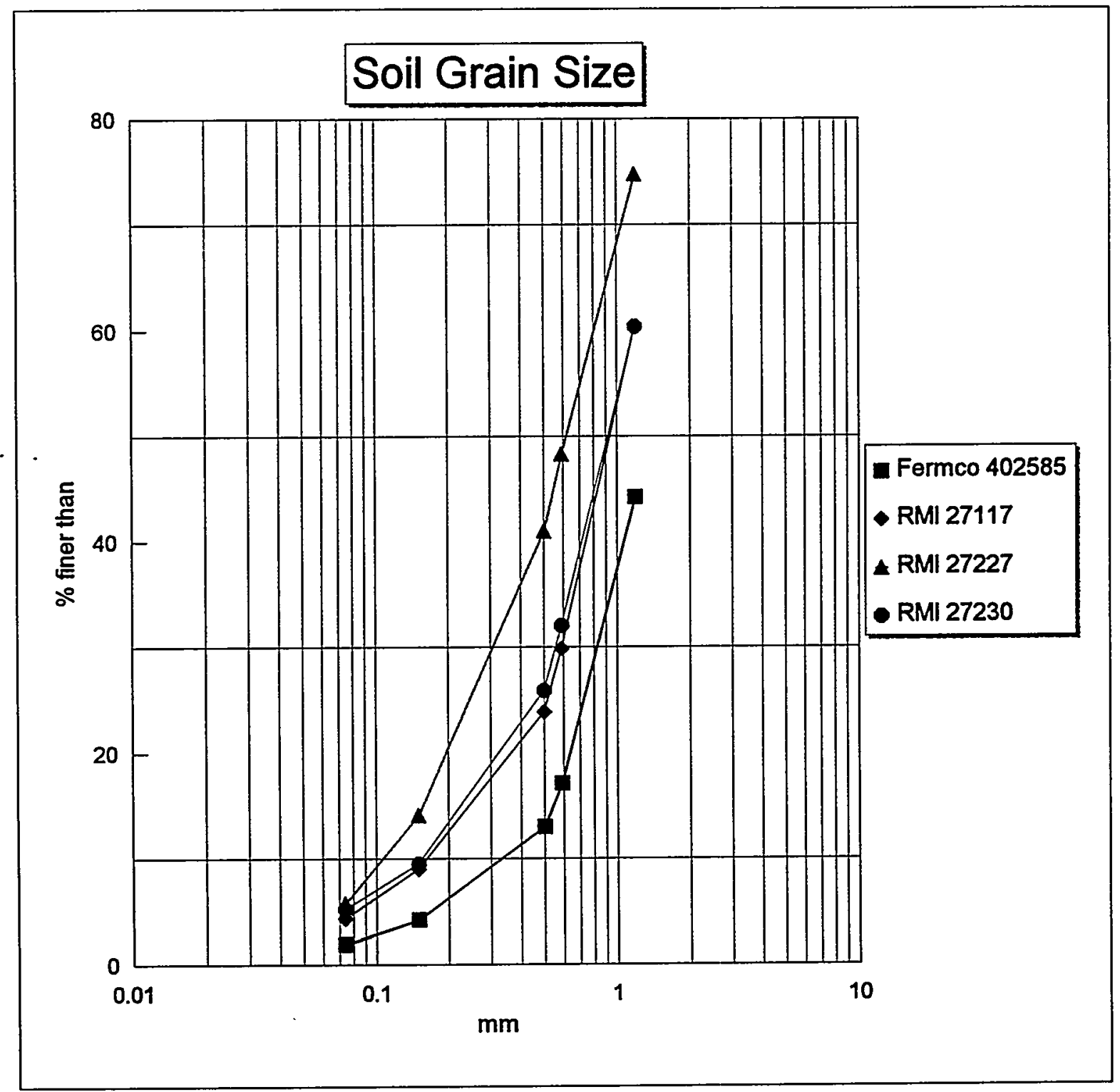

Figure 5 - Soil Grain Size 
Table 3

Soil Classification Based on Particle Size

Material

Clay

Silt

Very fine sand

Fine sand

Medium sand

Course sand

Very coarse sand

Very fine gravel

Fine gravel

Medium gravel

Coarse gravel

Very coarse gravel
Particle Size, $\mathrm{mm}$

$<0.004$

$0.004-0.062$

$0.062-0.125$

$0.125-0.25$

$0.25-0.5$

$0.5-1.0$

$1.0-2.0$

$2.0-4.0$

4.0-8.0

8.0-16.0

$16.0-32.0$

$32.0-64.0$

Table 4

Physical Characteristics and Grain Size Distribution of Studied Soils

\begin{tabular}{lllll} 
Sample & 402585 & 27117 & 27227 & 27230 \\
$\mathrm{~d}_{10}(\mathrm{~mm})$ & 0.35 & 0.17 & 0.12 & 0.17 \\
$\mathrm{U}_{\mathrm{c}}$ & 3.71 & 6.76 & 6.25 & 6.94 \\
$\% \mathrm{H}_{2} \mathrm{O}$ & 19 & 15 & 29 & 26 \\
$\%$ wt loss & 15 & 14 & 11 & 15 \\
$\mathrm{pH}$ soil/water & ND & 7.5 & 7.3 & 7.2 \\
\hline
\end{tabular}




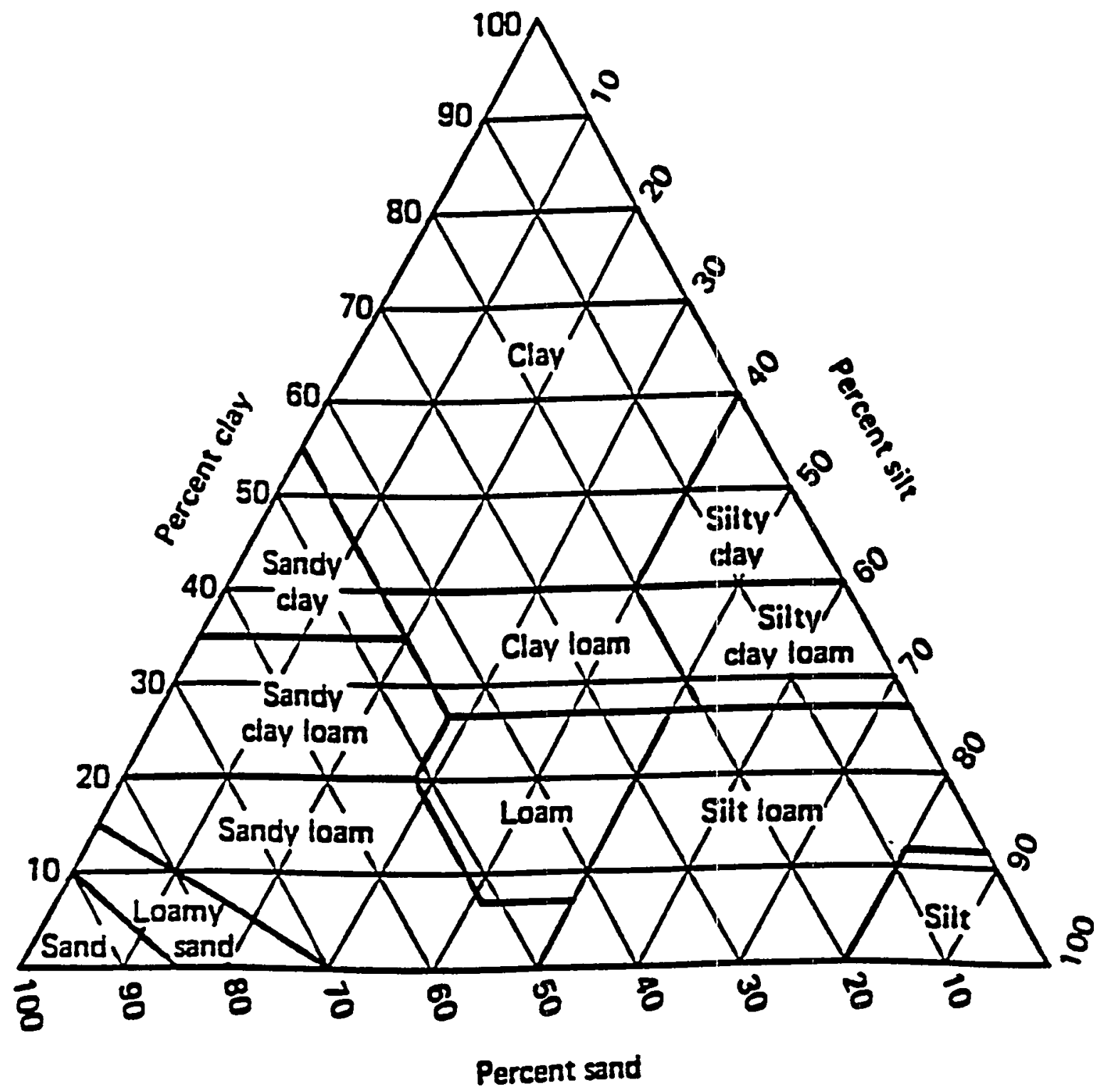

Figure 6: Triangle of Soil Textures 


\subsection{Solid Phase Extraction (SPE) for Technetium Concentration}

An objective of this experiment was to determine technetium-99 concentrations, at very low levels, in soils. Because liquid scintillation counting was to be the means of detection, the sample could not be contained in a harsh environment with a great deal of foreign material. There also had to be a means for concentrating the extracts so accurate concentrations could be obtained. It was reasoned that in order to extract technetium from the soil it would require oxidation with, perhaps, hydrogen peroxide. If technetium was in the soil it had to be reduced or anionically bound otherwise it would move with the groundwater as an anion. At pH 7 not many other troublesome metals would be very soluble. The goal was to oxidize technetium to pertechnetate $\left(\mathrm{TCO}_{4}^{-}\right)$then add tetrabutylammonium ion to it. Tetrabutylammonium ion forms an ion-pair with anions (Figure 7), making them more lypophilic (organic-like). This complex could then be collected and concentrated from an aqueous sample on a small Sep Pak $C_{18}$ cartridge. This technique is commonly used in high performance reverse phase ionpairing chromatography. Anions can be made more lipophilic using tetrabutylammonium ion and cations made more lipophilic using octanesulfonic acid. High performance reverse phase liquid chromatography (HPLC) makes use of an eighteen carbon chain molecule fixed to silica. This coated silica becomes very lipophilic and retains lipophilic molecules when it is used as a stationary phase in a column. Sep Pak $C_{18}$ cartridges, a product of Waters Associates, are small disposable columns used to remove bulk contaminants from samples and has the same properties as the $C_{18}$ used in analytical columns. A single test run using ${ }^{95 \mathrm{~m}} \mathrm{TCO}_{4}^{-}$and ${ }^{99} \mathrm{Tc}$ proved that as much as $200-300 \mathrm{ml}$ water could be passed over 


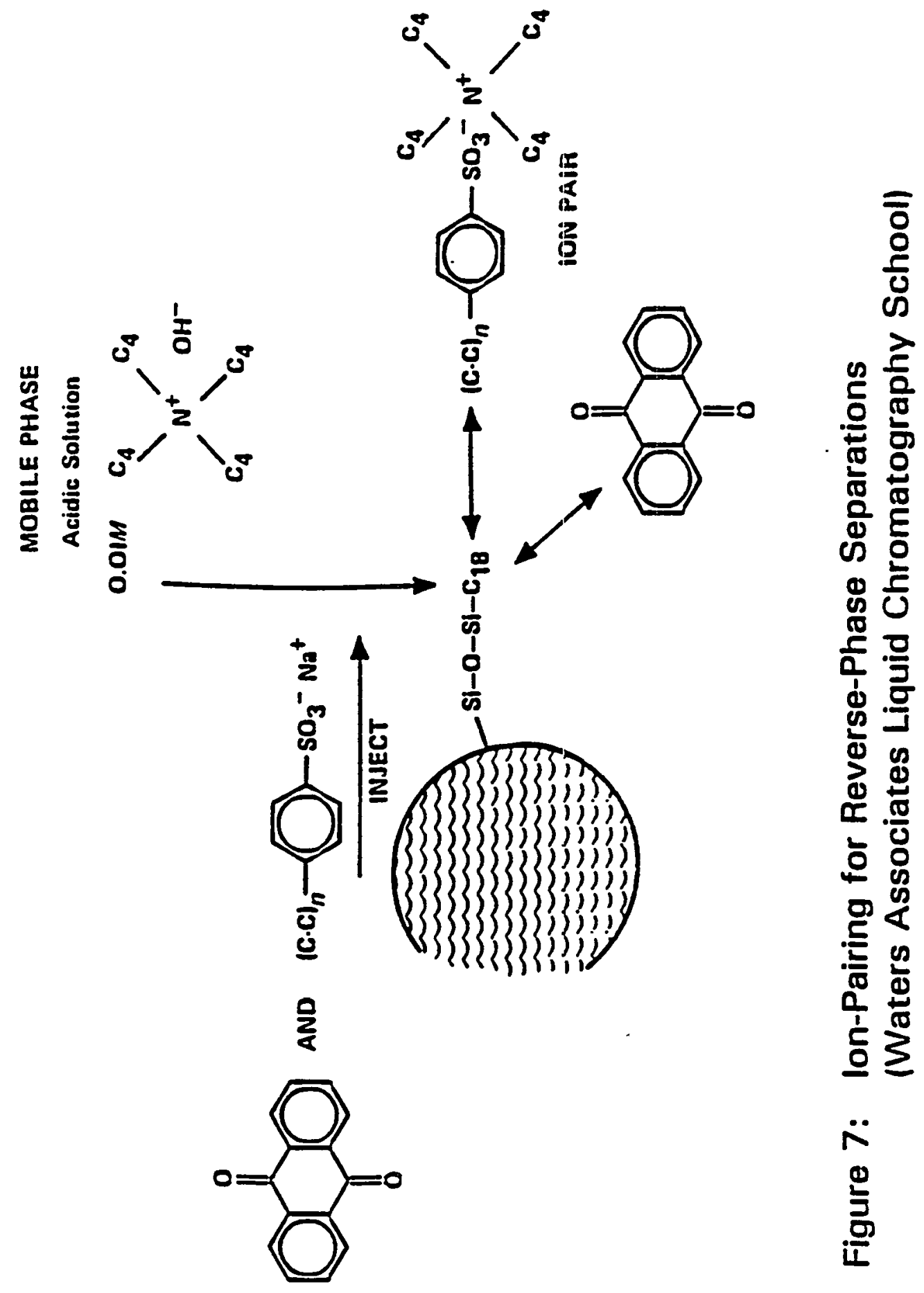


a $1 \mathrm{ml}$ column and retain all the technetium $\left(5.3 \mu \mathrm{g}{ }^{99} \mathrm{Tc}\right.$ was also present). Another test was run using a water extract of a 3.5 gram soil sample with ${ }^{95 \mathrm{~m}} \mathrm{TcO}_{4}{ }_{4}$ and ${ }^{99} \mathrm{Tc}$ added. Again all the activity was retained on the column. The SPE cartridge was first equilibrated by washing $10 \mathrm{ml} \mathrm{100 \%} \mathrm{methanol} \mathrm{through} \mathrm{the} 1 \mathrm{ml}$ column. Then $10 \mathrm{ml}$ water was washed through followed by $10 \mathrm{ml} 2 \times 10^{-3} \mathrm{M}$ in tetrabutyylammonium bromide. The sample was made $2 \times 10^{-3} \mathrm{M}$ in tetrabutylammonium bromide and passed through the column at about $2 \mathrm{ml} / \mathrm{min}$ (gravity feed column). Obviously the column has certain limitations. That is, the flow through the column can not be too fast as there must be enough residence time to interact with the stationary phase. Also technetium in large amounts or very large volumes may not be tolerated. Technetium was found to bind $100 \%$ under the above conditions $\left(5.3 \mu \mathrm{g}{ }^{99} \mathrm{Tc}\right.$, up to $300 \mathrm{ml}$ water and technetium as $\mathrm{TcO}_{4}{ }_{4}$ ). Behavior of technetium in the citric acid process was of interest so another sample containing technetium pertechnetate was made $0.2 \mathrm{M}$ in citrate $\mathrm{pH} 6$ and collected on a Sep Pak $\mathrm{C}_{18}$ cartridge. All of the technetium was retained on the Sep Pak. Three $\mathrm{ml}$ of $100 \%$ methanol was passed through the column to wash off the technetium. All of the technetium eluted completely. The methanol could be evaporated off and the resulting residue dissolved in water and counted for ${ }^{99} \mathrm{TC}$.

This technique was innovative in that it has never been used for technetium to the best of my knowledge. The use of agents such as methyltricaprylammonium chloride and tetrapropyl ammonium ion with subsequent liquid-liquid extraction (Salaria et al. 1963 and Foster et al. 1967) has been used. Basically these authors have made the technetium more lipophilic for subsequent extraction with chloroform. The attractive aspect of the SPE is that no harsh chemicals are used 
and it is conceivable that such a system could be used in the environment.

Columns are made with trimethylammonium exchange groups fixed to the silica stationary phase (Hamilton PRP-X100 columns). In principle an aqueous soil extract could be pumped through a large column packed with such a stationary phase. Occasionally the column would be washed with $100 \%$ methanol to remove the technetium and the column could be reused. The methanol could be distilled, collected and reused. The collected technetium could then be recovered in a very small volume and disposed of.

The above solid phase extraction has its limitations when a great deal of other ions are present. For example, in the citric acid extraction process, citric acid solubilizes many metals by forming complexes. These complexes may also form ion-pairs with tetrabutylammonium ion and compete for sites on the SPE media. This in fact does occur. Technetium-95m was added to a soil; then the soil was subsequently treated with $0.4 \mathrm{M} \mathrm{pH} 1.6$ citric acid. The extract was made $2 \times 10^{-3}$ $M$ in tetrabutylammonium ion and subjected to two Sep Pak $C_{18}$ cartridges in tandem. Only about $20 \%$ of the technetium was collected with an intense yellow band on the first cartridge and much lighter yellow band on the second cartridge. Both cartridges had the same amount of technetiunn-95m on them. I believe the iron citrate consumed all the ion-pairing agent, hence the intense color on the first cartridge.

Another consideration is that one must aggressively treat the residue soil after extraction to ensure all technetium has been removed. It is quite possible that a precipitate or oxide formation has trapped technetium such that peroxide and/or citrate can not dissolve the material trapping the technetium. A strong nitric acid 
treatment of the residual soil will ensure dissolution of metal oxides and oxidize organic material. Sep Pak $\mathrm{C}_{18}$ chromatography media has $\mathrm{pH}$ limitations between 2 and 8, operating at either extreme for too long would result in dissolution of silica (stationary material). It was decided that methyl ethyl ketone (MEK) extraction of samples made $2.5 \underline{N}$ in sodium hydroxide would be the preferable choice, to recover technetium, under such conditions as described above. The MEK could be evaporated thereby concentrating the technetium.

\subsection{Pertechnetate Extractions with MEK from $2.5 \mathrm{~N} \mathrm{NaOH}$.}

Methyl ethyl ketone extraction of pertechnetate in an environment of large amounts of metal precipitate is extremely efficient. Working with one soil (27117), ${ }^{95 m} \mathrm{TCO}_{4}$ was added to the soil, extracting one sample with water only; another with $0.4 \mathrm{M} \mathrm{pH} 1.6$ citric acid. Initially, a wrist action shaker was used; however, the range of motion was such that some soil remained on the bottom of the vessel, not ensuring good mixing. It was found that by placing 2-3 grams of soil in a separatory funnel with $20 \mathrm{ml}$ of water or citric acid and applying a vacuum to the top of the flask while opening the stopcock slightly provided very good mixing. This was the technique subsequently used throughout the remainder of the experiments. The soil was contacted with water or citric acid as described above for about 4-6 hours. The extract was collected after centrifugation of the soil/water using $5000 \mathrm{~g}$ for 20 minutes. The extract was removed and an additional $20 \mathrm{ml}$ of extractant added and extracted for 1 hour. All extracts were combined, made $2.5 \underline{\mathrm{N}}$ in $\mathrm{NaOH}$ then extracted with $20 \mathrm{ml}$ MEK. Because of the large amount of metal precipitate a phase separation could not be obtained. The MEK extract and soil had to be centrifuged at $5000 \mathrm{~g}$ for 10 minutes. With the 
added ${ }^{95 \mathrm{~m}} \mathrm{TcO}_{4}$ it was immediately evident that another $20 \mathrm{ml}$ extraction was necessary. About $90 \%$ of the technetium was recovered in the extracts. Upon centrifugation there was a buffy gelatinous precipitate in the bottom of the centrifuge tube with an intense yellow colored solution above it followed by a white gelatinous precipitate with the MEK layer on the very top. The MEK extracts were combined and the MEK distilled off via a rotary evaporator. The residual ${ }^{99} \mathrm{Tc}$ was dissolved in $2.5 \mathrm{ml} 0.1 \mathrm{M} \mathrm{NH} \mathrm{NH}_{4} \mathrm{OH}$ followed by an additional $2.0 \mathrm{ml} 0.1 \underline{\mathrm{M} \mathrm{NH}} 4 \mathrm{OH}$ wash. The added ${ }^{95 \mathrm{~m}} \mathrm{TcO}_{4}{ }_{4}$ indicated two rinses were necessary for a quantitative recovery.

The residual soils from the water and citrate extract were transferred to beakers and made $50 \%$ V/V in nitric acid and heated to dense nitrogen dioxide vapors. The beakers were cooled and made $2.5 \mathrm{~N} \mathrm{NaOH}$ after adding a calculated amount of $\mathrm{NaOH}$ to neutralize the acid. This mixture was extracted with $2-20 \mathrm{ml}$ MEK aliquots for complete recovery of added ${ }^{95 \mathrm{~m}} \mathrm{TcO}_{4}{ }_{4}$. As before, centrifugation was necessary for phase separation. It is important to note that no significant ${ }^{95 m} \mathrm{TcO}_{4}^{-}$was lost in the nitric acid digestion step as there reports of technetium volatility in some acids. Since it was necessary to centrifuge the extracts to get a phase separation, it was more tidy and efficient to carry out the MEK extractions in $50 \mathrm{ml}$ screw top propylpropylene centrifuge tubes.

In summary, MEK efficiently extracts technetium in the presence of large amounts of precipitated metals. Practically, since centrifugation is necessary for phase separation, plastic centrifuge tubes work quite nicely. The use of added ${ }^{95} \mathrm{TCO}_{4}^{-}$indicated that recoveries during extraction and nitric acid digestion were very good. To quantitatively recover the technetium after MEK removal, two 
washes are necessary. Contact of soils with extractant can be effected very efficiently in a separatory funnel to which a vacuum has been applied. In the environmental setting sucking air through a soil is preferred in that any volatiles can be easily cold-trapped. It is then not necessary to be concerned about releasing pollutants to the atmosphere. Of course practically using a vacuum may not be possible.

\subsection{Reducing capability of Soils}

The four studied soils were weighed ( 3.5 grams) into $50 \mathrm{ml}$ plastic centrifuge tubes and $0.3 \mathrm{ml}$ of $1.69 \times 10^{-4} \mathrm{M}\left(5\right.$ micrograms) ${ }^{99 \mathrm{~m} \mathrm{TCO}_{4}^{-}}$and $0.07 \mathrm{ml}^{\circ}{ }^{95 \mathrm{~m}} \mathrm{TcO}_{4}^{-}$ (30 microcuries) added, plus $2.0 \mathrm{ml}$ water. A nitrogen atmosphere was used to blanket the upper atmosphere of the tube. The samples were placed in a water bath at $37^{\circ} \mathrm{C}$ for twelve days with constant swirling. One gram of each of the samples were placed into platinum crucibles with the same amount of technetium with $1.0 \mathrm{ml}$ of water. After twelve days the samples in the centrifuge tubes were extracted with water and the extracts subjected to paper chromatography. The activity migrated with an Rf of 0.66 as does technetium pertechnetate. The soils did not, under laboratory conditions, get reduced. The samples in the platinum crucibles were ashed at $500^{\circ} \mathrm{C}$ with no loss of technetium.

In conclusion for this aspect of the study, the soils did not readily reduce technetium. Soil samples may be ashed at $500^{\circ} \mathrm{C}$ without loss of technetium. However, if technetium is physically trapped within a metal precipitate high temperatures may render the metal oxide acid insoluble. Refractory oxides are very difficult to dissolve. This concern was not addressed here and should be studied if ashing is preferred. 


\subsection{Counting Samples for Radioactivity:}

Low levels counts of ${ }^{99 \mathrm{~m}} \mathrm{Tc}$ and ${ }^{95 \mathrm{~m}} \mathrm{Tc}$ on chromatographic samples were counted in the LKB gamma counter monitoring the 140 , and $240 \mathrm{KeV}$ peaks with a wide energy window. Multi-microcurie levels of technetium used in the development of the procedures were followed using an Atomlab 100 dose calibrator. Technetium-99 counts were measured in a Beckman LS7800 liquid scintillation counter. Generally 1-2 milliliters of extract containing ${ }^{99} \mathrm{Tc}$ was added to 5-10 milliliters of Packard Ultima gold XR scintillant, mixed and counted one or two days later. To a second aliquot of the same sample ${ }^{99} \mathrm{Tc}$ was added. The standard addition allows one to determine if there is significant loss of counts or quenching. Liquid scintillation counting does not specifically identify the betaemitting isotope. Some chemicals can produce a response with scintillant. That is one reason for allowing the samples to stand one or two days before counting. All counts were compared to an NIST traceable ${ }^{99} \mathrm{Tc}$ standard. Appendix II illustrates a calculation of the specific activity of ${ }^{99} \mathrm{Tc}$ and tabulates the disintegrations per minute, corresponding curie content, and mass of technetium.

Samples that were counted by liquid scintillation counting were counted for at least 30 minutes each to result in a relative standard deviation of \pm 2 percent. It is necessary to consider the background counts relative to the sample counts. The standard deviation of the net source activity, sample (A) background (B) is

$$
\sigma=\sqrt{\sigma_{A}^{2}+\sigma_{B}^{2}}
$$

and the optimum counting time is found from 


$$
\frac{t_{B}}{t_{A}}=\sqrt{\frac{r_{B}}{r_{A}}} \text { (Willard et al 1965). }
$$

The minimum counting time to achieve a predetermined precision is found by comparing sample counts, background counts and desired relative standard deviation and inspection of Figure 8. The standard deviation in activity measurements is the square root of the number of counts taken.

$$
\sigma=\sqrt{N}
$$

In the samples generally 100 counts per minute were found and 30 minute counts collected for a total of 3000 counts so $\sigma=\sqrt{3000}=55$ counts. The relative standard deviation in percent is

$$
100 \sigma=\frac{100}{\sqrt{N}}
$$

in the above work

$$
100 \sigma=\frac{100}{\sqrt{3000}}= \pm 1.88
$$

Fifty picocuries, or 3 nanograms of technetium can be counted easily with confidence compared to $20-60$ nanograms by colorimetric methods. 
MEINKEN - 36

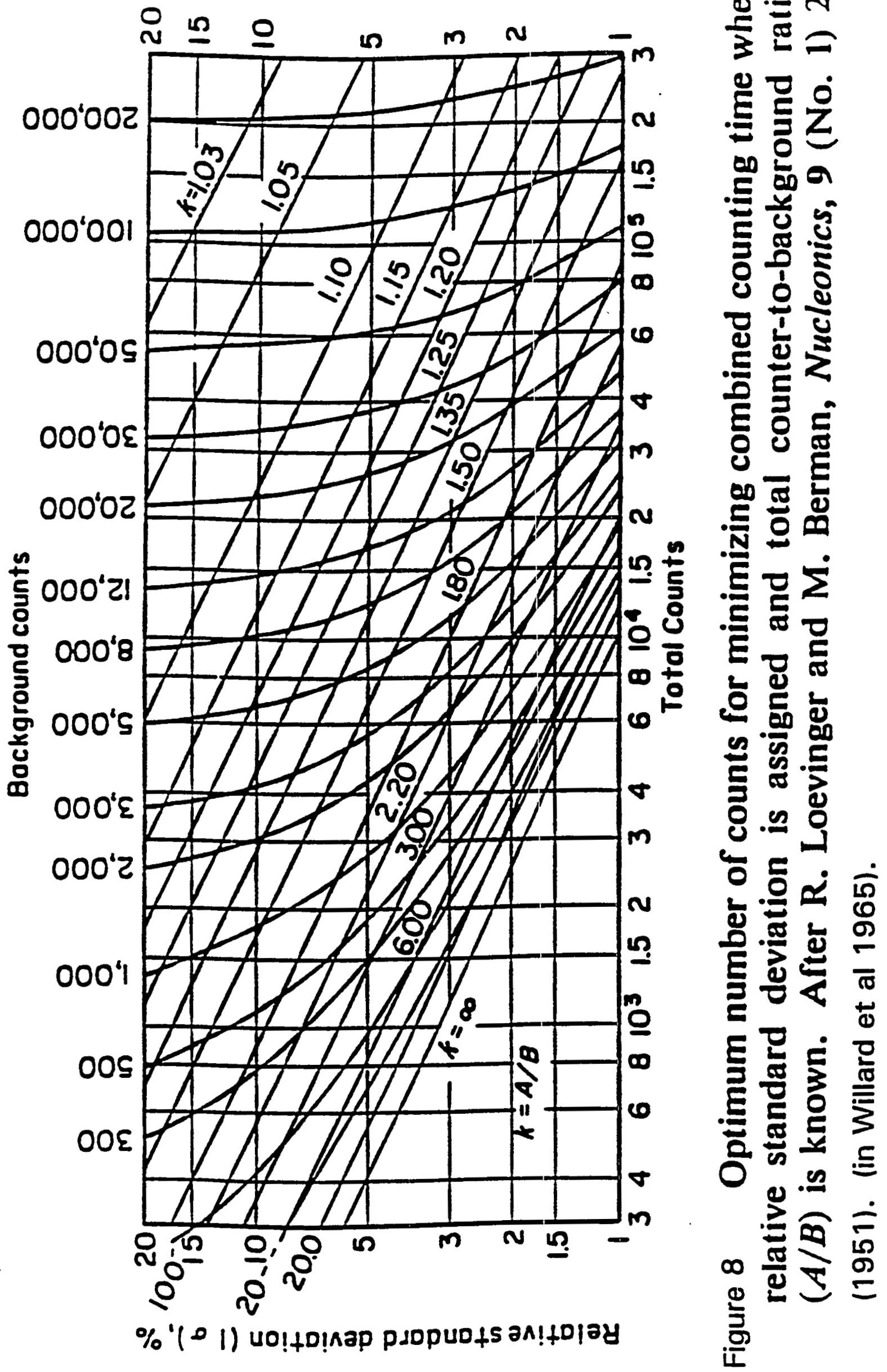


Extracted soil samples were checked for gamma emitting isotopes by using a multichannel analyzer with a germanium detector. Samples were counted for 1-2 hours to determine the presence of such isotopes.

One method used for beta isotope identification is to use gas proportional scintillation counters with an aluminum absorber. Count the isotope of interest with and without an absorber and compare to a known. If the ratios are comparable, the isotope is probably the same. Feather (Fried et al. 1951) developed an equation, $E=1.92 R^{0.725}$, where $E$ is the energy in $\mathrm{MeV}$ and $\mathrm{R}<0.3$ $\mathrm{g} / \mathrm{cm}^{2} \mathrm{Al}$ to be used in measurements with aluminum absorbers to determine the energy of the beta-emitters. This method would be unreliable for the identification of a mixture of beta emitters having beta energies lower than ${ }^{99} \mathrm{Tc}$. Those lower energies would be absorbed and go undetected. Inductively coupled plasma spectroscopy interfaced to a mass spectrometer (ICP/MS) is another method to identify the beta-emitter. Parts per billion of technetium could be detected by ICP/MS limiting the ${ }^{99} \mathrm{Tc}$ detection to nanocurie amounts. Researchers that have such sophisticated equipment will not allow the use of such instrumentation with radioactive material.

It may be possible to identify the isotope producing the response in liquid scintillation by high performance liquid chromatography. If the sample is chromatographed using ion-pairing reverse phase chromatography with a U.V. detector that could monitor numerous wavelengths, it in principle should be possible to see a couple of hundred picocuries. The flow cell in most HPLC U.V. detectors is a 1 centimeter cell path with a volume of about 8 microliters. With a $C_{18}$ stationary phase and the buffer system previously described, a large volume of 
aqueous solution containing ${ }^{99} \mathrm{Tc}$ could be injected and completely retained. The technetium could be released in a small volume by washing the column with methanol. Using the molar absorptivity of $6220 \mathrm{cr}^{-1}$ at $2440 \AA$ an absorbance of 0.1 could be obtained if $1.27 \times 10^{-2}$ micrograms or 216 picocuries were injected (see Appendix III) and eluted in 8 microliters. Most HPLC U.V. detectors have attenuation down to 0.01 absorbance units full scale. With wavelength absorbance measurements at 2440 and $2870 \AA$ a great degree of confidence in identifying the isotope as ${ }^{99} \mathrm{Tc}$ would be obtained. This is quite possible with modern day diode array U.V. detectors with stopflow capabilities. If a colorimetric complex was first formed and then chromatographed on an HPLC with the same flow cell the sensitivity could be amplified by the increase in molar absorptivity ratio. So if a technetium complex had a molar absorptivity of $52000,{ }^{99} \mathrm{TcO}_{4}$ detection would be increased $52000 / 6220$ or 8.4 times.

\subsection{Distillation of Technetium in Soils with Sulfuric Acid:}

The literature indicates that technetium can be distilled from sulfuric acid (Meyer et al. 1975). It was reasoned that rather than extract the soil with water or citrate and have to digest the residual soil with $\mathrm{HNO}_{3}$ it could be done all in one step by sulfuric acid digestion of the whole soil sample. This was attempted without success, using ${ }^{95 \mathrm{~m}} \mathrm{TcO}_{4}^{-}$very little technetium distilled over. Meyer states that technetium begins to distill at $110^{\circ} \mathrm{C}$ and continues over a large temperature range. Complete distillation is not achieved until 0.5 to $1 \mathrm{ml}$ sulfuric acid remains. This poses a serous problem in collecting and counting the technetium. It would still be necessary to concentrate the technetium by MEK/2.5 $\mathrm{N}$ NaOH extraction. 
Sulfuric acid is very difficult to neutralize and work with safety. Since this method did not work as had been expected, it was not pursued.

\subsection{Determination of ${ }^{99} \mathrm{Tc}$ Levels in Soils Studied:}

Each of the four soils studied were extracted with water or $0.4 \mathrm{M}$ citric acid with and without hydrogen peroxide for 4 hours and overnight. The residual soil from the water or citric acid extraction (process 1 and 2) was treated with $50 \%$ $\mathrm{HNO}_{3}$ (process 3 ) to remove any strongly bound technetium. All extracts were made $2.5 \underline{\mathrm{N}}$ in $\mathrm{NaOH}$ and extracted with MEK. The MEK extracts combined and MEK distilled off by rotary evaporation and resulting residue dissolved in $0.1 \mathrm{M}$ $\mathrm{NH}_{4} \mathrm{OH}$. Aliquots were taken for liquid scintillation counting as described above. The resulting data was tabulated as picocuries per gram of soil.

A detailed description of the procedure follows:

Weigh 2.5 grams of air dried soil into a $125 \mathrm{ml}$ separatory funnel; add $20 \mathrm{ml}$ of water or $0.4 \mathrm{M} \mathrm{pH} 1.6$ citric acid. In experiments using hydrogen peroxide add $2 \mathrm{ml}$ of $30 \% \mathrm{H}_{2} \mathrm{O}_{2}$. Apply a vacuum to the top of the funnel then slowly open the stopcock to allow air to provide mixing. Allow to mix for 4 hours or overnight. Transfer soil and extract to a centrifuge tube to separate soil from aqueous layer. Remove the aqueous layer to a $50 \mathrm{ml}$ plastic centrifuge tube. Repeat extraction in a separatory funnel with another $20 \mathrm{ml}$ of water or citrate and mix for 1 hour. Collect the aqueous extract as before. Combine extracts; make the extracts $2.5 \underline{N}$ in $\mathrm{NaOH}$. Extract 1-2 minutes with $20 \mathrm{ml}$ MEK in a $50 \mathrm{ml}$ centrifuge tube using a vortex mixer. Centrifuge to get a phase separation. Remove the MEK layer to a rotary evaporator tube. Repeat an extraction with another $20 \mathrm{ml}$ of MEK. Centrifuge again and combine the MEK extracts. Rotary evaporate the MEK off. 
Dissolve the resulting residue by washing the tube vigorously with $2.5 \mathrm{ml}$ of $0.1 \mathrm{M}$ $\mathrm{NH}_{4} \mathrm{OH}$ using a vortex mixer. Repeat with $2.0 \mathrm{ml}$ then combine washes and mix. Take $2.0 \mathrm{ml}$ directly for liquid scintillation counting after adding $5 \mathrm{ml}$ scintillant. Take a second aliquot of $2.0 \mathrm{ml}$ from the same sample and add $0.1 \mathrm{ml}{ }^{99} \mathrm{Tc}$ of a known concentration; add $5 \mathrm{ml}$ scintillant. Mix samples well and determine that only one phase is present. Count by liquid scintillation counter at least one day later.

The residual soils from the above extracts are transferred to $100 \mathrm{ml}$ beakers using water to transfer and an equal volume of concentrated nitric acid added ( 5 ml). Add a stir bar and heat on a hot plate until brown $\mathrm{NO}_{2}$ vapors evolve. Let cool then add enough $\mathrm{NaOH}$ pellets to neutralize the $\mathrm{HNO}_{3}$ and make $2.5 \mathrm{~N}$ in $\mathrm{NaOH}$. Extract with MEK as before using centrifuge tubes. Rotary evaporate off the MEK and process as before with previous extracts.

\subsubsection{Addition of Technetium-99m Tracer to Soils for Procedure Development}

Technetium-99m was added to the aqueous extract of one of the soils to be analyzed for the procedure development and to address recovery and volatilization losses. The intent was to use ${ }^{99 \mathrm{~m}} \mathrm{TcO}_{4}^{-}$because it has a $140 \mathrm{KeV}$ gamma emission that could be easily monitored, then allow the technetium to decay and perform beta counting for the technetium-99.

Two and one-half grams of soil $\mathbf{2 7 1 1 7}$ were weighed into two separate separatory funnels. Sample A was extracted with $20 \mathrm{ml} 0.4 \mathrm{M} \mathrm{pH} 1.6$ citric acid after adding $0.08 \mathrm{ml}$ of ${ }^{99 \mathrm{~m}} \mathrm{TcO}_{4}^{-}$(about 855 microcuries) with application of a vacuum to the top of the funnel and opening the stopcock to provide air mixing. Sample B was extracted with $20 \mathrm{ml}$ of water, again adding $0.08 \mathrm{ml} \mathrm{of}^{99 \mathrm{~m}} \mathrm{TcO}_{4}^{-}$and 
effecting mixing as in A. No hydrogen peroxide was added to either sample. Mixing was effected for about eighteen hours. Another sample, $\mathrm{C}$ was extracted in a similar fashion using citric acid with 3 hours mixing. A $0.08 \mathrm{ml}$ counting standard was added to a separate tube as a reference for following the activity in the samples. The extracts were centrifuged then filtered through a 0.45 micrometer filter. To samples $A$ and $B$ tetrabutylammonium bromide was added to make its concentration $2 \times 10^{-2} \underline{\mathrm{M}}$. Each sample was then eluted through two Sep Pak $C_{18}$ cartridges after proper equilibration as described in section 3.4. Four milliliter fractions of effluent were collected for each sample. It became immediately evident that the citrate extracted sample was not retained by the SPE media. Yellow color eluted through as did most of the ${ }^{99 \mathrm{~m}} \mathrm{TcO}_{4}^{-}$. The $\mathrm{B}$ sample, the ${ }^{99 m} \mathrm{Tc}$ extracted with water was completely retained by the SPE and completely eluted with a $5 \mathrm{ml}$ methanol wash. Sample $\mathrm{C}$ was made $2.5 \mathrm{~N}$ in $\mathrm{NaOH}$ and was extracted with MEK as described in section 3.8.1. Through the use of the added ${ }^{99 \mathrm{~m}} \mathrm{TcO}_{4}{ }^{-}$it was determined that two MEK extractions were necessary to recover all of the ${ }^{99 \mathrm{~m}} \mathrm{TCO}_{4}^{-}$. The MEK was rotary evaporated off and residue dissolved and transferred to another tube. By following the ${ }^{99 \mathrm{~m}} \mathrm{TcO}_{4}{ }^{-}$activity it was evident that a second wash of the rotary evaporated tube was necessary to recover all of the technetium.

Technetium-99m was added to the residual soils from the above water and citric acid extracted samples. These residual soils were transferred to a beaker using a small volume of water and $5 \mathrm{ml}$ of concentrated nitric acid was added to each. Each of the samples were digested on a hot plate until brown nitrogen dioxide vapors and vigorous boiling resulted. The samples were cooled and 
checked for loss of ${ }^{99 \mathrm{~m}} \mathrm{TcO}_{4}{ }^{-}$. No technetium-99m was lost. The samples were then transferred to centrifuge tubes and centrifuged at $10000 \mathrm{~g}$ for 30 minutes and the supernatant removed. It was necessary to wash the residual soil with water, re-centrifuge and collect the wash. Combining it with the supernatant resulted in less than $1 \%$ of the activity remaining in the soil. The MEK was removed and samples redissolved as before. About $85-90 \%$ of the technetium- $99 \mathrm{~m}$ extracted leaving about $10-15 \%$ in the precipitate from the metals precipitated in this step. The ${ }^{99 \mathrm{~m}} \mathrm{TcO}_{4} \cdot$ was allowed to decay and then the samples were counted for ${ }^{99} \mathrm{Tc}$ by liquid scintillation counting. There appeared to be many more counts than expected in these samples. The $0.08 \mathrm{ml}$ of added ${ }^{99 \mathrm{~m}} \mathrm{TcO}_{4}^{-}$was checked by liquid scintillation counting and found to contain many counts. This was not a true test because the samples were extracted from $2.5 \mathrm{~N} \mathrm{NaOH}$ with MEK. Another $0.08 \mathrm{ml}$ of the same source of ${ }^{99 \mathrm{~m}} \mathrm{TCO}_{4}^{-}$was so extracted and produced the same response. Gamma counting on another aliquot was performed, counting for six hours. It was demonstrated that a small amount of molybdenum.99 was present. This is not unusual in that milkings from a ${ }^{99} \mathrm{Mo} /{ }^{99 m} \mathrm{Tc}$ generator must be checked for ${ }^{99} \mathrm{Mo}$ breakthrough before used in humans. The value must be below a certain level. In these samples such a small amount of ${ }^{99 \mathrm{~m}} \mathrm{TCO}_{4}^{-}$was used, one would not have thought this would be a problem.

This aspect of the work demonstrated some very valuable information. It established the necessary conditions needed to recover technetium using the MEK extraction method. Water extracted technetium could be adsorbed on a SPE using an actual samples. The concern of volatilization of technetium during nitric acid digestion was unfounded. And a lesson was learned that anything added to the 
sample may produce a response in the beta counting. It also demonstrated that alkaline soluble metals may very well get extracted with MEK. This is what happen with the molybdenum-99. So if other alkaline soluble radioactive metals are present this should be addressed.

\subsubsection{Beta Response from Uranium-238}

Based on the experiment in 3.9 the question arose that since these samples contain uranium, what would the response be in liquid scintillation counting if some uranium was present. Uranium-238 has a $45 \mathrm{KeV}$ gamma emission and its decay produces a series of alpha emitters (Fig 9) (Friedlander et al. 1966). An aliquot, $0.01 \mathrm{ml}$ of $200 \mathrm{nM} \mathrm{UO}{ }_{2}\left(\mathrm{NO}_{3}\right)_{2}$ or 0.476 nanograms was added to scintillant and counted. Eleven hundred counts resulted. This was not how the samples were treated, however. The same size aliquot was added to two separate test tubes. To one, $1.0 \mathrm{ml}$ water was added to another, $1.0 \mathrm{ml} 0.1 \mathrm{M} \mathrm{pH} 3$ citrate was added. One milliliter of $5 \underline{\mathrm{N} \mathrm{NaOH}}$ was added to each and then each extracted two times with $2 \mathrm{ml}$ MEK. The MEK removed, the residue dissolved as before and counted. No significant counts over background were found. This experiment demonstrated that uranium and its daughter products would not extract from $2.5 \mathrm{~N} \mathrm{NaOH}$ with MEK and produce a response in liquid scintillation counting. It also shows that if some uranium is carried over into the beta counting a response may be produced but not due to ${ }^{99} \mathrm{Tc}$. 


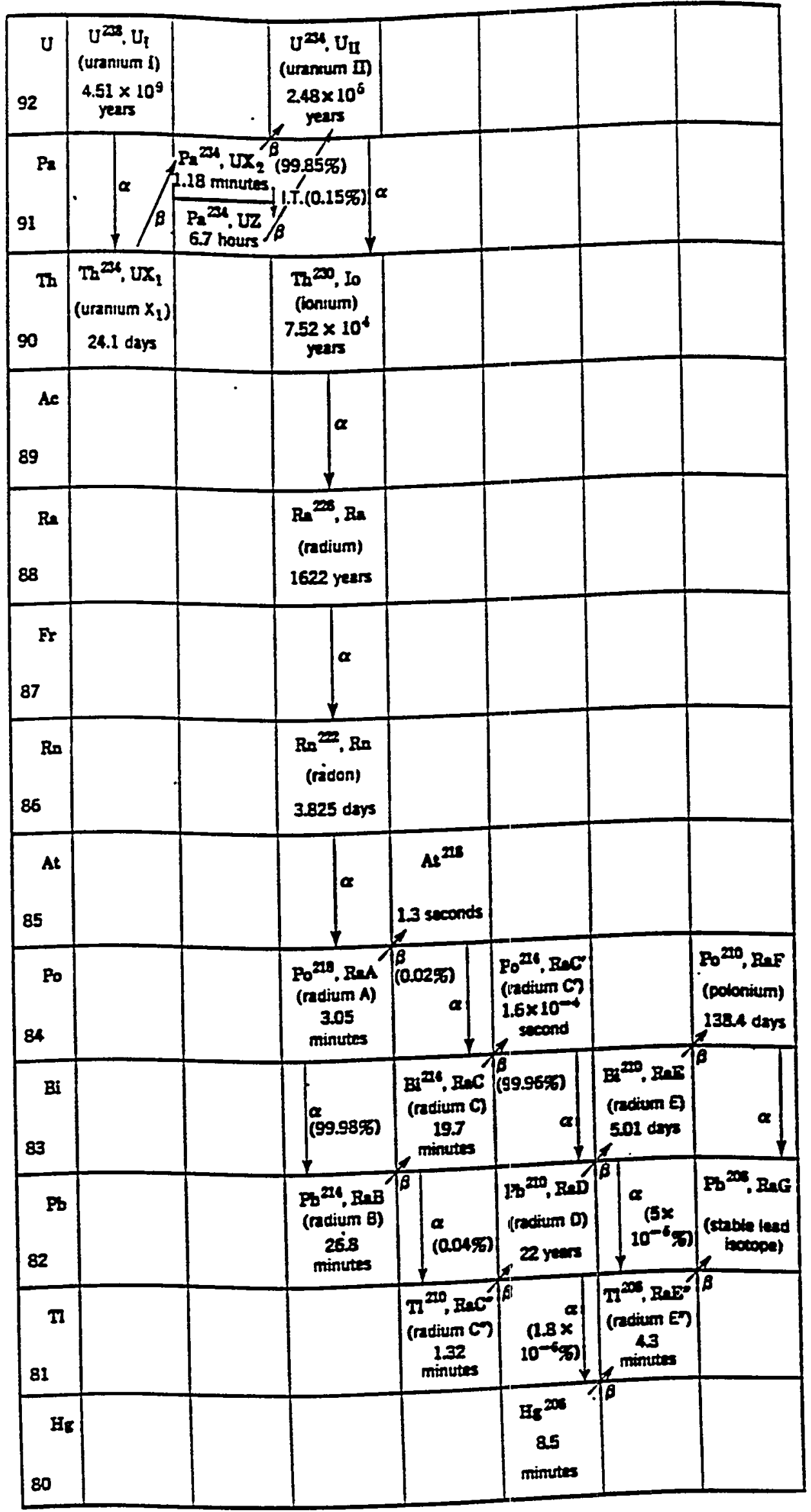

Figure 9 The Uranium Series (from Friedlander, et al. 1966) 


\subsubsection{Extraction of Four Soils With Water/Hydrogen Peroxide and Citric Acid/Hydrogen peroxide with Second Digestion of Residual Soil}

The purpose of this aspect of the experiment was to determine the amount of ${ }^{99} \mathrm{Tc}$ in the soils using water and hydrogen peroxide as an extractant. Another set of the four soils were extracted with citric acid and hydrogen peroxide. The results were compared. The once nitric acid digested soils were re-digested and extracted to determine if all the technetium was recovered.

Two and one-half grams samples of each of the four soils were extracted in a separatory funnel with the appropriate extractant as previously described for four hours. The samples were worked up as described in section 3.9.1 $\mathrm{No}^{99 \mathrm{~m}} \mathrm{TCO}_{4}{ }^{-}$ was added and only MEK extraction was used. Table 5 shows the comparison of water and citric acid extracted values.

Each of the residual soils from the above water $/ \mathrm{H}_{2} \mathrm{O}_{2}$ were re-digested with nitric acid. The supernatant reextracted with MEK as previously described and processed. Liquid scintillation counting demonstrated that no significant counts were recovered.

The results demonstrated that reasonably precise data could be obtained (except for 27117 process 2 \& 2-3). Sample 402585 was not stated to contain any ${ }^{99} \mathrm{Tc}$ and the poor count rate and results demonstrate that no technetium is present. This sample acted as a negative control. That is, no response was produced because there was no technetium there. 
Table 5

Comparison of ${ }^{99} \mathrm{Tc}$ Concentration for Water and Citric Acid Extracted Soils

\begin{tabular}{||c|c|c|c|c|c|c|c|c||}
\hline \multicolumn{5}{|c|}{ Water Extracted } & \multicolumn{4}{c||}{ Citric Acid Extracted } \\
\hline Sample & pci & Process & $\%$ & pci/g & (pci) & process & $\%$ & pci g \\
\hline \hline 27117 & 46.2 & $(1)$ & 39.6 & 46 & 165 & 2 & 52.1 & \\
& 70.4 & $(1-3)$ & 60 & & 151.6 & $2-3$ & 47.9 & 117 \\
\hline 27227 & 90.3 & 1 & 50.8 & & 108.9 & 2 & 51.5 & \\
& 87.2 & $1-3$ & 49.2 & 64 & 102.7 & 2.3 & 48.5 & 68 \\
\hline 27230 & 64.3 & 1 & 44.5 & & 52.4 & 2 & 45.7 & \\
& 80.2 & $1-3$ & 55.5 & 57 & 62.1 & $2-3$ & 54.3 & 44 \\
\hline 402585 & 17 & 1 & 74 & & 12.9 & 2 & 100 & \\
& 6 & $1-3$ & 26 & 9 & 0 & $2-3$ & & 5 \\
\hline
\end{tabular}

Process $1=$ water $/ \mathrm{H}_{2} \mathrm{O}_{2}$ extraction

Process 1-3 $=$ nitric acid digestion of water extracted soil

Process 2 = citric acid/ $\mathrm{H}_{2} \mathrm{O}_{2}$ extraction

Process 2-3 = nitric acid digestion of citric acid extracted soil.

3.9.4 One Soil Extracted by Two Methods of Agitation for Different Times Without Hydrogen Peroxide

The purpose of this experiment was to determine if there is a difference in effectiveness if the samples were agitated by air bubbling in a separatory funnel or mixed by wrist-action shaker. Another variable was time and no hydrogen peroxide was used. Four 2.5 grams samples were weighed. Two, 2.5 gram samples were transferred to two $125 \mathrm{ml}$ separatory funnels and extracted as previously 
described, with $20 \mathrm{ml} 0.4 \mathrm{M}$ citric acid without added hydrogen peroxide for four hours. The samples were centrifuged, supernatant recovered and saved and the residual soil washed with water. Two, 2.5 gram samples were transferred to $50 \mathrm{ml}$ polypropylene centrifuge tubes and $20 \mathrm{ml} 0.4 \mathrm{M} \mathrm{pH} 1.6$ citric acid added and extracted overnight ( $\sim 18$ hours) on a wrist action shaker. The samples were worked up as previously described. The results are shown in the following table.

Table 6

Separatory Funnel Agitation Versus Wrist Action Shaker Extraction of ${ }^{99} \mathrm{Tc}$ from Soil 27227

\begin{tabular}{||l|l|l|l|l|l|l|l|l||}
\hline \multicolumn{5}{|c|}{ Separatory funnel } & \multicolumn{4}{c||}{ Wrist Shaker } \\
\hline process & $\begin{array}{l}\# 1 \\
\mathrm{pci}\end{array}$ & $\%$ & $\begin{array}{l}\# 2 \\
\mathrm{pci}\end{array}$ & $\%$ & $\begin{array}{l}\# 3 \\
\mathrm{pci}\end{array}$ & $\%$ & $\begin{array}{l}\# 4 \\
\mathrm{pci}\end{array}$ & $\%$ \\
\hline \hline 2 & 59 & 48.1 & 54.8 & 42.4 & 101.8 & 58.2 & 64.8 & 47.8 \\
\hline $2-3$ & 63.6 & 51.9 & 74.5 & 57.6 & 67.4 & 41.8 & 52.5 & 52.2 \\
\hline $\mathrm{pci} / \mathrm{g}$ & 49.5 & & 51.5 & & 70 & & 54.6 & \\
\hline
\end{tabular}

ave: $56.4 \pm 9 \mathrm{pci} / \mathrm{g}$

Combining above with 3.9.2 data for $27227(64,68.1)$ ave: $59.6 \pm 8.9 \mathrm{pci} / \mathrm{g}$ 
The results from the above experiment demonstrate that the method of agitation at the 2.5 gram may be either of the two methods. However, the air bubbling separatory funnel was run four hours and the shaker about 18 hours. Visually the air bubbling appears to provide better contact, any carbon dioxide buildup is vented and air bubbling ensures an oxidative environment to ensure technetium oxidation. It also demonstrated that hydrogen peroxide was not necessary. The data also suggests that water extraction is as effective as citric acid. (The $64 \mathrm{pci} / \mathrm{g}$ valve from the previous experiment was one determination using water $\left./ \mathrm{H}_{2} \mathrm{O}_{2}\right)$. The use of citric acid does result in a clearer less gelatinous mass to subsequently extract with MEK. In all these extractions using citric acid and nitric acid the solutions are quite yellow suggesting the presence of large amounts of iron or organic material. The 402585 sample was only lightly colored and also did not have any technetium within the soil. It is of importance to note that about $50 \%$ of the ${ }^{99} \mathrm{Tc}$ is fairly easily extracted. The remaining $50 \%$ must be removed by aggressive use of nitric acid.

\subsubsection{Fate of Technetium and Uranium During Bioremediation, of Contaminated}

\section{Soil. Using The BNL Citric Acid Process}

The behavior of technetium using ${ }^{95 m} \mathrm{Tc}$ in the bioremediation process using the citric acid extraction process was studied using soil number 27117. Figure 10 shows a flow diagram outlining the steps followed. Fifteen grams of soil was weighed into acid washed $500 \mathrm{ml}$ polypropylene centrifuge bottles. One hundred fifty milliliters of $0.4 \mathrm{M} \mathrm{pH} 1.6$ citric acid was added and placed on a wrist action shaker overnight in the dark, to prevent photodecomposition. The samples were 


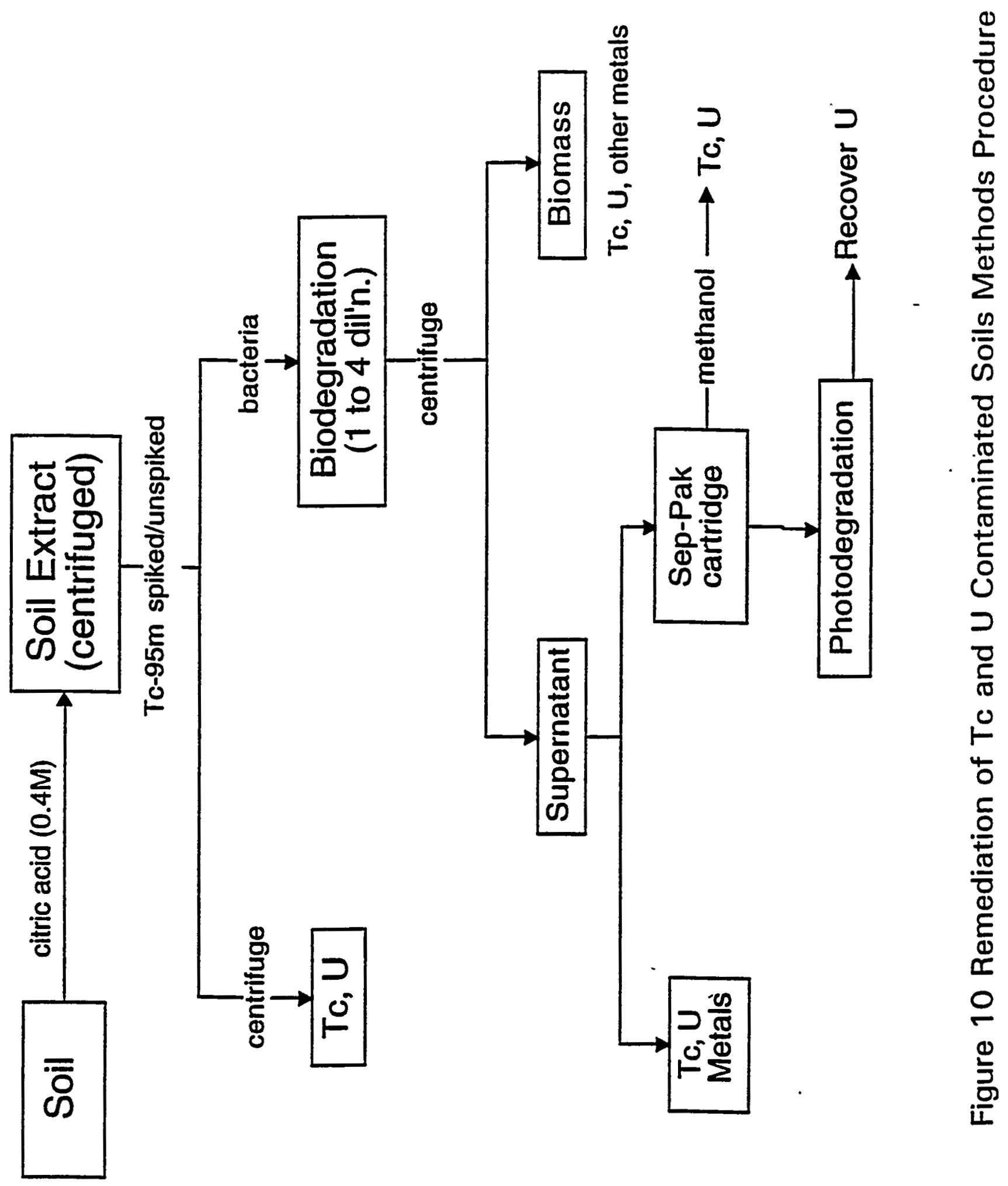


then centrifuged at $9000 \mathrm{~g}$ for 20 minutes. The supernatant were collected and combined and the $\mathrm{pH}$ determined. A $10 \mathrm{ml}$ aliquot was filtered through a 0.45 micrometer filter and acidified with $0.5 \mathrm{ml}$ concentrated hydrochloric acid. This sample was for subsequent metals analysis to be used as a starting concentration reference. The soils were washed two times for 15 minutes on a wrist action shaker with $100 \mathrm{ml}$ of water. Twenty-five milliliters of this wash was preserved with $0.5 \mathrm{ml}$ concentrated $\mathrm{HCl}$. (Note: My BNL mentors designed and performed this experiment. I carried out the sampling and experiments using ${ }^{95 \mathrm{~m}} \mathrm{Tc}$.)

The bacterial inoculum was Pseudomonas fluorescens; ATCC \#55241 prepared in modified Simmon's citrate medium. The medium contains: 2.0 grams anhydrous citric acid, 1 gram ammonium chloride, 1 gram each of monobasic and dibasic potassium phosphate, 4 grams of sodium chloride and 0.2 grams of magnesium sulfate in $1000 \mathrm{ml}$ with a $\mathrm{pH}$ of 6.5 .

A medium containing 2.0 grams ammonium chloride, and 2.0 grams each of mono and dibasic potassium phosphate was dissolved, $\mathrm{pH}$ adjusted to 6.5 and diluted to 1.5 liters. Thirty $\mathrm{ml}$ of the medium was added to each of $12,125 \mathrm{ml}$ erlenmeyer flasks stoppered with cotton plugs and autoclaved. The flasks were labeled $\mathrm{G}-1$ to $\mathrm{G}-12$. Ten milliliters of the filtered citric acid and $\mathrm{pH} 6.5$ adjusted extracts from soil 27117 were added to each of the flasks. Flasks $1,2,3,7,8,9$ were inoculated with $2 \mathrm{ml}$ of $P$. fluorescens for a total volume of $40 \mathrm{ml}$. One tenth of a milliliter containing about 1.5 microcuries of ${ }^{99 \mathrm{~m}} \mathrm{TcO}_{4}{ }^{-}$was added to flasks $\mathrm{G}-7$ through G-12. A counting standard of $0.1 \mathrm{ml}$ was taken and adjusted to $2.0 \mathrm{ml}$. This was to be used as a reference to which all samples were to be compared. 
The standard was actually 20 times more dilute because of the counting rate. The flasks were then placed in a waterbath at $26^{\circ} \mathrm{C}$ in the dark. A zero time $4.0 \mathrm{ml}$ aliquot was removed from each flask aseptically before adding ${ }^{95 \mathrm{~m}} \mathrm{Tc}$. This aliquot was filtered through a 0.45 um filter and preserved with $0.2 \mathrm{ml}$ concentrated $\mathrm{HCl}$ for subsequent citric acid and uranium analysis. Because analysis of the samples were to be performed in two separate buildings, contamination control was essential. Because of this concern only flasks G-1 through G-6 were analyzed for citric acid and uranium at one location, building 318. Flasks G-7 through G-12 were analyzed for uranium and technetium at building 801 , in radiologically controlled laboratories.

Samples were taken at $0,24,48,72,96$ and 120 hours, aseptically removing $4.0 \mathrm{ml}$ aliquots for analysis. All of the samples were measured for $\mathrm{pH}$ and absorbance at $600 \mathrm{~nm}$ to monitor bacterial growth. Samples from flasks G-1 through G-6, the unspiked (with ${ }^{95 \mathrm{~m}} \mathrm{Tc}$ ) were then filtered through a 0.45 um filter and preserved with $0.2 \mathrm{ml}$ concentrated $\mathrm{HCl}$. The spiked samples, flasks G-7

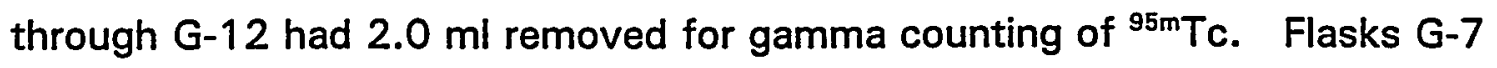
through G-12 also were measured for $\mathrm{pH}$ and absorbance at $600 \mathrm{~nm}$. The spiked samples were then 0.45 um filtered and a $2.0 \mathrm{ml}$ aliquot was taken and counted. A total of $4.0 \mathrm{ml}$ was removed from the spiked flasks. When all the measurements were made, the samples were preserved with $0.2 \mathrm{ml}$ concentrated $\mathrm{HCl}$ for subsequent uranium analysis. At the conclusion of the experiment the samples were centrifuged at $10000 \mathrm{~g}$ and the supernatant collected and measured for $\mathrm{pH}$, citric acid, technetium and uranium. The biomass was transferred to weighed 
crucibles and dried to constant weight at $60^{\circ} \mathrm{C}$. The dried biomass was then digested in hot nitric acid, diluted to a known volume, filtered and analyzed for technetium-99 and uranium. In the course of the experiment the $\mathrm{pH}$ measurements showed that there was an increase in $\mathrm{pH}$ of the inoculated samples. This demonstrated that the bacteria were destroying the citric acid; hence, an increase in the $\mathrm{pH}$ resulted. In the un-inoculated flasks there was no change in $\mathrm{pH}$ nor increase in absorbance at $600 \mathrm{~nm}$ indicating no bacterial growth; hence, aseptic techniques and sterility was maintained. The absorbance increased rapidly in the incubated flasks. It was necessary to first centrifuge the samples at $5000 \mathrm{~g}$ for 10 minutes before filtration in order to filter the samples through a 0.45 um filter.

The spiked un-inoculated filtered samples seem to demonstrate a loss of $25 \%$ of activity compared to the counting standard and the filtered inoculated samples. At the conclusion of the experiment one inoculated sample (G-7) and one un-inoculated sample (G-12) were carefully analyzed to determine if ${ }^{95 \mathrm{~m}} \mathrm{Tc}$ was getting reduced by the citric acid extract. An aliquot of the filtered and unfiltered samples were analyzed over a $0.9 \times 30 \mathrm{~cm} \mathrm{G-25} \mathrm{M} \mathrm{Sepadex} \mathrm{column.} \mathrm{If}$ technetium-95m was reduced there would be a poor activity recovery from the column and a retention different than that of pertechnetate $\left({ }^{99 \mathrm{~m}} \mathrm{TcO}_{4}{ }^{-}\right)$. The columns were first calibrated using ${ }^{99 \mathrm{~m}} \mathrm{TcO}_{4}^{-}$. Analysis showed technetium as $\mathrm{TcO}_{4}^{-}$. A reasonable explanation for the loss of $25 \%$ of the activity for the un-inoculated filtered sample compared to the counting standard and the filtered inoculated sample is as follows. A nylon 66 membrane filter was used. Many of these filters have some anionic exchange capacity. The inoculated samples have a great deal of 
bacterial growth, hence a large amount of protein. The protein in the inoculated samples neutralize some of the charge on the filters; whereas, the un-inoculated samples do not have any protein to do the same. Hence, there is a loss of activity in the filtered un-inoculated samples by anionic adsorption.

At the conclusion of the experiment, the spiked inoculated samples G-8 and G-9 were centrifuged at $10000 \mathrm{~g}$, filtered through a 0.45 um filter then $4.0 \mathrm{ml}$ of each were passed over one Sep Pak $C_{18}$ cartridge using the techniques described in section 3.4. All of the technetium (99\%) was retained on the Sep Pak $C_{18}$ cartridges for both samples and $5 \mathrm{ml}$ methanol completely removed the ${ }^{99 \mathrm{~m}} \mathrm{TcO}_{4}^{-}$. It is important to keep in mind that the volume passed over these SPE's represent only the extract of about 0.1 grams. For example: $(15$ grams soil $/ 150 \mathrm{ml})(10 \mathrm{ml})=1 \mathrm{gram} ;(1 \mathrm{gram}) 4 / 40 \mathrm{ml}=0.1 \mathrm{gram}$ soil. However, technetium was retained suggesting that the bulk of the metals contained in the soil were removed, thereby eliminating any interference with the absorption of ${ }^{99 \mathrm{~m}} \mathrm{TCO}_{4} \cdot$ on the Sep Pak cartridge.

The combined supernatant from the biodegradation experiment was filtered through a 0.45 um filter and $\mathrm{pH}$ adjusted to $\mathrm{pH} 3.5$. The filtered extract was transferred to four sterile $250 \mathrm{ml}$ erlenmeyer flasks and three of the flasks were placed in a light bank apparatus containing eight 60 watt high output fluorescent growth lights. The fourth flask was kept in the dark to serve as a control. Three $\mathrm{ml}$ of the exposed samples were periodically taken on two of the exposed samples filtered using a 0.45 um filter and analyzed for $\mathrm{pH}$ and organic acids. Then these samples are preserved with $0.05 \mathrm{ml}$ nitric acid (Ultrex) and subsequently analyzed 
for technetium and uranium. The third exposed sample was used to obtain a mass balance for the precipitate.

At the conclusion of the photodegradation experiment the samples are centrifuged at $10000 \mathrm{~g}$ and the supernatant removed. The supernatant is filtered and analyzed for $\mathrm{pH}$, citric acid, technetium and uranium. The solid from the centrifuged sample is dried to constant weight at $60^{\circ} \mathrm{C}$; then digested in hot nitric acid and analyzed for technetium and uranium.

While the above experiment was being performed in building 801 a parallel experiment at building 318 was performed without the use of radioactivity. This parallel experiment served as a control.

These samples are currently being processed so the results are not available at this time.

\subsection{Comparison of Technetium Soil Content with Independent Laboratory}

An independent laboratory analyzed the three soils of interest 27117 , 27227,27230 . There were sent the unextracted soils and citric acid extracts along with the extracted soils. The comparison follows:

\section{Table 7}

Comparison of Technetium Results for Contaminated Soil Samples

\begin{tabular}{|c|c|c|c|c|}
\hline Sample & (n) & BNL (pci/g) & $n$ & $\begin{array}{c}\text { Independent Laboratory } \\
\text { (pci/g) }\end{array}$ \\
\hline \hline 27117 & 2 & $81 \pm 50$ & 2 & $120 \pm 7$ \\
\hline 27227 & 6 & $56 \pm 9$ & 2 & $109 \pm 15$ \\
\hline 27230 & 2 & $50 \pm 9$ & 2 & $144 \pm 47$ \\
\hline
\end{tabular}


The independent laboratory used a procedure developed by Oak Ridge National Laboratory (Rickard 1980) (ORNL). The procedure is as follows:

1. Pipet an aliquot of sample plus an aliquot of $10 \mathrm{mg} 1 \mathrm{ml}$ potassium perrhenate carrier in water into a separatory funnel or extraction vial. The perrhenate is standardized by adding known amounts of technetium to the carrier, precipitating, washing and counting and weighing the precipitate, causing precipitation with tetraphenylarsonium chloride (TPA) $10 \%(\mathrm{w} / \mathrm{v})$.

2. Add $10 \mathrm{ml} 2 \mathrm{M}$ sodium carbonate and $1 \mathrm{ml} 30 \% \mathrm{H}_{2} \mathrm{O}_{2}$, swirl.

3. Add $30 \mathrm{ml}$ MEK and extract for 1 minute.

4. Remove MEK and re-extract.

5. Drain organic extract into an erlenmeyer and take to dryness.

6. Dissolve the dried residue with water and two drops of concentrated hydrochloric acid, 5 drops of $10 \mathrm{mg} / \mathrm{ml}$ of ruthenium and cerium and 2 drops of 10 $\mathrm{mg} / \mathrm{ml} \mathrm{Fe}^{+3}$ as ferric nitrate. Swirl then centrifuge.

7. Filter supernatant into a centrifuge tube and adjust acidity with $6 \mathrm{M} \mathrm{HCl}$ until methyl orange indicator turns to pink (red to yellow $\mathrm{pH}$ 3.2-4.4). Use a gamma spectrometer to check for purity.

8. Cool the tube in an ice bath, then add $0.2 \mathrm{ml}$ of TPA.

9. Centrifuge the white tetraphenylarsonium perchenate precipitate and wash twice with ice water.

10. Dissolve the washed precipitate with acetone and transfer to a tared aluminum disk (planchette). Dry under a heat lamp. Reweigh, calculate radiochemical yield and beta count in an end-window counter $\left({ }^{99} \mathrm{Tc}=3.5 \times 10^{7} \mathrm{dpm} / \mathrm{mg}\right)$. Perrhenate is 
used as a radiochemical carrier for technetium. Rhenium and technetium are separated from most of the fission products by solvent extraction with MEK from alkaline solution. They are then scavenged from residual fission products using ruthenium, cerium and iron, then coprecipitated with tetraphenylarsonium chloride. The purified technetium activity (beta $0.3 \mathrm{MEV}$ ) is counted. Corrections are applied based on the radiochemical carrier recovery.

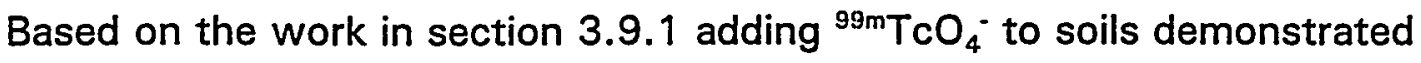
that all the technetium could be recovered without adding carrier perrhenate. In addition re-extraction of the re-digested soils demonstrated that all the technetium was recovered. I can not find any obvious flaws in the procedure used in this work. In addition the precision of the sample analyzed six times was very impressive. It is possible in the ORNL procedure used, some other radioactive . material other than ${ }^{99} \mathrm{Tc}$ is coprecipitated with the perrhenate. As previously demonstrated (see section 4.0) if uranium is carried along a response will be produced in liquid scintillation counting. Another possibility is the precipitation technique may be a source of over correction. Precipitation techniques are tedious and losses can result easily upon washing of the precipitate. The results are corrected based on a weight recovery of perrhenate tetraphyenlarsonium chloride.

In any event a future experiment using the ORNL procedure is in order as there may be something not being considered that may be the source of the difference. 


\section{Chapter 4}

Results of Investigation

It is readily evident from the work presented that something as simple as extracting an element from soil can be quite complicated. Extensive chemistry research into technetium's use in nuclear medicine has been demonstrated to be very useful. Some simple chromatographic techniques commonly used in radiopharmaceutical research makes the determination of technetium's chemical form relatively easy.

The use of spectrophotometric methods and the above mentioned chromatographic techniques provided useful tools in the demonstration that a technetium citrate complex could be produced by reduction of technetium in an $\mathrm{HCl} / \mathrm{Kl}$ environment with subsequent complexation with citrate at $\mathrm{pH} 3$. This experiment was designed to enable one to look at the possible bioremediation of ${ }^{99} \mathrm{Tc}$ citrate by Pseudomonas fluorescens bacteria without the presence of other metals. It was found that a large molar excess (100-300 times) of citrate was needed to ensure complexation without hydrolysis. The work also demonstrated that citrate at $\mathrm{pH} 6$ forms a complex more readily than at $\mathrm{pH} 3$. The use of stannous tin ensures a more rapid reduction of pertechnetate with rapid complexation.

It was demonstrated that if technetium is in a water environment at neutral $\mathrm{pH}$ it can readily be absorbed on a $\mathrm{C}_{18}$ stationary phase chromatographic media through the use of an ion-pairing agent. One is applying the use of HPLC chromatographic techniques. With the availability of stationary phase media 
already coupled with trimethylammonium ion, it may be possible to use such media in the environmental setting. The limitations of the techniques must be addressed. A serious limitation is the presence of soluble citrate metal complexes.

Through the use of gamma emitting ${ }^{99 m} \mathrm{TCO}_{4}^{-}$and ${ }^{95 m} \mathrm{TcO}_{4}^{-}$it was demonstrated that recovery of extracted technetiurn can be very efficient in actual soil samples. The use of gamma emitters allows for great sensitivity of detection with immediate results. This allows for the rapid development of procedures to be used in the analysis and remediation of contaminated soils.

Liquid scintillation counting is a far more sensitive means of detection than colorimetric methods. However, it is difficult to specifically identify the element being counted. Feather analysis uses aluminum absorbers to absorb all the counts to identify the energy. However, if there is a spectrum of low energy beta emitters the analysis becomes less clear. It would be more reassuring to identify the element giving a beta response by using inductively coupled plasma spectroscopy interfaced to a mass spectrometer. Since most researchers do not want to contaminate such an expensive sophisticated instrument, the HPLC techniques suggested in section 3.7 may provide the necessary information.

The extraction of soils with water or citric acid indicated that about $50 \%$ of the technetium is readily extractable. The remaining technetium had to be recovered by more aggressive treatment with nitric acid. It may be possible to eliminate the need for nitric acid digestion by repeating the citric acid extraction with heat and or repeated extractions. Citric acid is $\mathrm{pH} 1.6$ and has the added advantage of complexing the metals in a less hazardous environment. Interestingly, 
there was always the presence of an intense yellow color associated with the recovery of technetium. It is strongly surmised that the technetium is bound by reduction with ferrous iron and perhaps layering of the iron as it hydrolyzes thereby physically trapping the reduced hydrolyzed technetium. This iron hydroxide protects the technetium from oxidation and hence migration in the soil. There is soluble iron associated with fulvic acid type compounds. These yellow materials are called Gelbstoffe (Manahan 1994). Fulvic acid is a humic substance, which is a class of complexing agents formed by the decomposition of vegetation. These substances occur as deposits in soils, peats, marshes and in any location where there is vegetation decomposition.

It may be possible to determine if technetium is associated with fulvic acid if one can extract the complex without air oxidation. If this complex can be extracted without oxidation of technetium to pertechnetate, and complexing agents do stabilize reduced technetium, then the extract may be analyzed over a gel filtration media such as Bio-Gel P-2 (Bio-Rad Laboratories). This media has a separation range of 100-1800 daltons. Fulvic acid has a molecular weight of 666 . If the technetium elutes in this molecular weight range, then it is probably bound to fulvic acid. One could take another approach. Obtain fulvic acid and try to reduce technetium with ferrous iron in the presence of fulvic acid and perform the proper chromatography.

In the citric acid toxic metal leaching process, citric acid will not complex technetium that is already hydrolyzed. Citrate may solubilize metals that are trapping the reduced technetium thereby allowing the technetium to oxidize to 
pertechnetate and become mobile. Using Pseudomonas fluorescens bacteria in this aerobic process did not reduce the technetium. In addition once the toxic metals were precipitated technetium could be collected on a Sep Pak $\mathrm{C}_{18}$ cartridge and collected by removal with methanol. Pertechnetate behavior with anaerobic bacteria should be studied. Another interesting experiment would be to form ${ }^{99} \mathrm{Tc}$ citrate as described in sections 3.2.1 and 3.2.2 and subject it to $P$. fluorescens. 


\section{Chapter 5}

\section{Conclusions}

Technetium in its oxidized form is anionic and moves with the groundwater, having high mobility. However, many chemicals may reduce technetium easily. Once technetium gets reduced it becomes immobile unless there is a high concentration of complexing agent to keep it soluble and mobile. Deep in the ground, ferrous iron, sulfhydryl containing compounds and numerous other chemicals may reduce technetium rendering it immobile. It is almost impossible to predict with certainty the behavior of technetium in a particular geologic environment because certain chemicals that can reduce technetium may also be present. One can only use the published data to know where to start to look for technetium. Generally, technetium may bind to soils that have anionic exchange capacity or soils high in organic content or high ferrous containing soils. If the technetium is not physically trapped, it should be readily oxidizable through the use of hydrogen peroxide.

If presented with an unknown contaminated soil an approach taken might be that of Fig 11. First determine as much history of the sample as to location and what processes may have occurred at that location. Try to determine the chemicals that may have entered this soil. Check groundwater for the presence of

${ }^{99} \mathrm{Tc}$ and other gamma emitting isotopes. Determine the type of soil and $\mathrm{pH}$, moisture content and organic content. Review the literature as to how technetium behaves in this type of soil. If technetium is contained in the soil it is there probably because the soil has anionic exchange capacity or the technetium got 


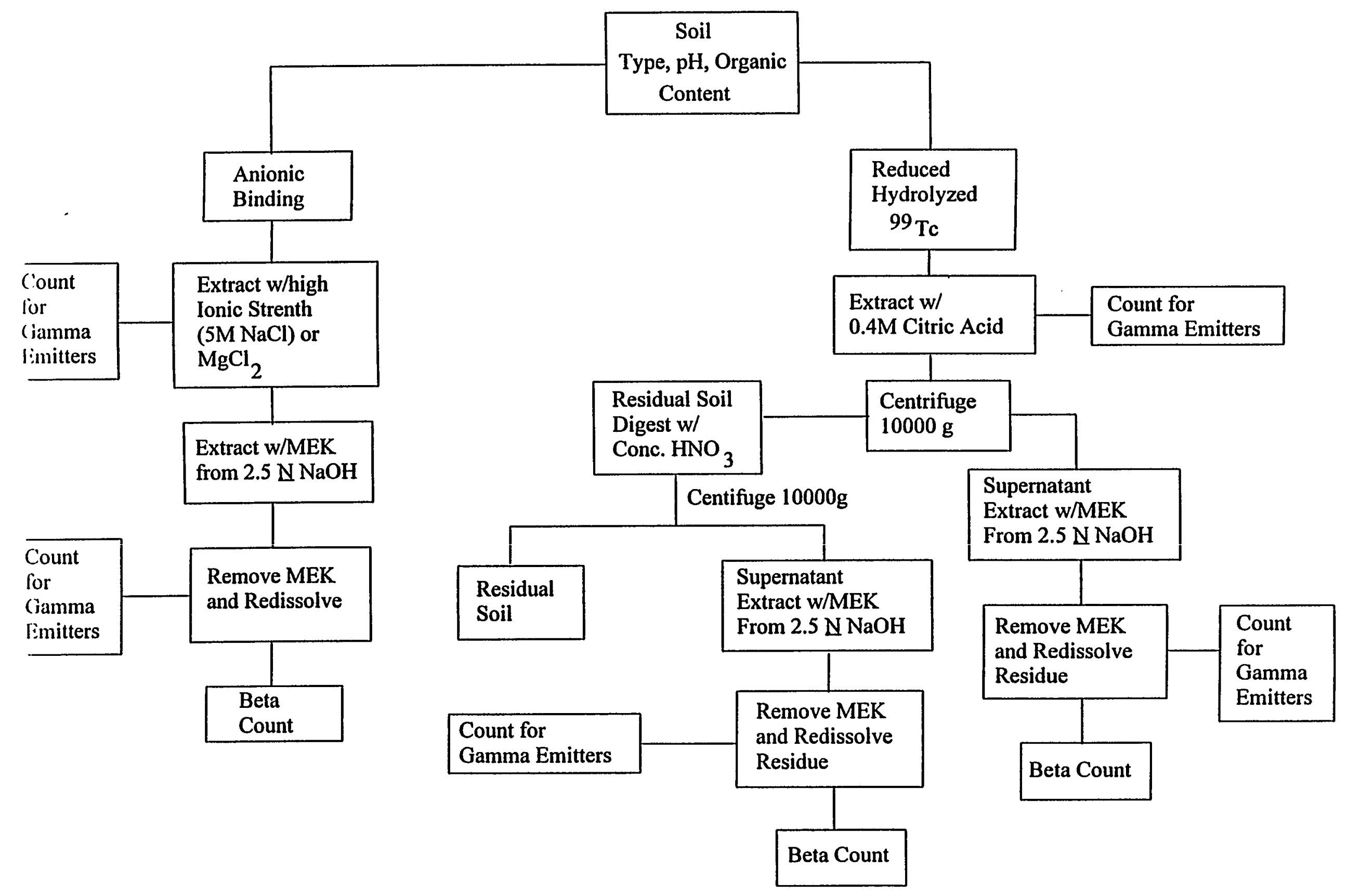

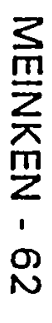

FIGURE 11 Methods Procedure for Extraction of ${ }^{99}$ Te from Soil 
reduced and hydrolyzed. The right side of the flow chart was used in this work and is reliable. The left side has not been evaluated here but is logical. I would evaluate it by spiking the soil with ${ }^{95 m} \mathrm{TcO}_{4}{ }^{-}$or if not available use ${ }^{99 \mathrm{~m}} \mathrm{TcO}_{4}$. Technetium-99m costs about $\$ 0.65$ per millicurie but one must be licensed to use this material.

It may be possible to extract technetium from soils with hydrogen peroxide and water using a solid phase extraction media. If the technetium is not physically trapped it may be completely recovered. The column could be regenerated by removing the technetium with methanol. Recycling of the methanol would be possible by rotary evaporation and collection. The technetium could be recovered in very small volumes.

Citrate in the citric acid toxic metal leaching process probably solublizes metals that reduce and physically trap technetium. This process allows technetium to be subjected to oxidation to pertechnetate. Studies must be performed to determine the behavior of pertechnetate if carried further in the bioremediation by bacteria. Technetium-95m and chromatographic techniques will certainly be useful for this study.

The four soils studied were sandy in character with only $15-20 \%$ organic material with some limestone as evidenced by evolution of gas on contact with citric acid. A portion of the technetium associated with the soils was readily extractable with water or citrate. Another fraction was more firmly bound to the soil, probably trapped upon reduction in the presence of ferrous iron. 
To conclude, it is important to understand how technetium behaves in various types of soil, but it is essential to treat each test area individually. It is not possible to completely reproduce the conditions of a particular sampling area to predict the behavior of technetium. Reducing conditions and the presence of various elements will influence the behavior of technetium in the environment. Previous studies should be used as a guide in anticipating the behavior of technetium in a particular setting. 


\section{Literature Cited}

Birks, J.L. "Medical Radionuclides in marine environments." Nature 255 (1975): $621-622$.

Bondietti, E.A., Francis, C.W. "Geologic migration potentials of technetium-99 and neptunium-237". Science 203 (1979): 1337-1340.

Boyd, G.E., Larson, Q.V. "Solvent extraction of heptavalent technetium". J. Phys. Chem. 64 (1960): 988-996.

Boyd, G.E., "Technetium and promethium". J. Chem. Ed. 36(1) (1962): 436-442. Crouthamel, C.E. "Thiocyanate spectrophotometric determination of technetium". Anal. Chem. 29 (1957): 1756-1760.

. Curtis, David B. "Geochemical controls on ${ }^{99} \mathrm{Tc}$ transport and retention". Chemical Geology. 55 (1986): 227-231.

Del Cul, G.D., Bostick, W.D., Trotter, D.R., and Osborne, P.E. "Technetium-99 Removal from process solutions and contaminated groundwater". Separation Science and Technology 28 (1-3) (1993): 551-564.

Eckelman, W., Meinken, G., Richards, P. "The chemical state of ${ }^{99 m} \mathrm{Tc}$ in biomedical products II. The chelation of reduced technetium with DTPA". J. Nucl. Med. 113 (1972): 577-581.

Feigl, Fritz, Anger, Dr. Vinzenz. Spot Test in Inorganic Analysis Trans. 6th ed. Oesper, Ralph E. Amsterdam, The Netherlands: Elsevier, 1972.

Foster, Robert E., Maeck, William J., Rein James E. Analytical Chemistry 39 No. 6 (1967): 563-566. 
Foti, S. Delucchi, E. Akamian, V. "Determination of picogram amounts of ${ }^{99} \mathrm{Tc}$ by neutron activation analysis". Anal. Chem. Acta. 60 (1972): 261-268.

Francis, A.J. and Dodge, C.J. "Removing Radionuclide and Toxic Metals from Contaminated Soil." U.S. Patent No. 5,292,456, (1994).

Fried, Sherman, Jaffey, A.H., Hall, N.F., Glendenin, I.E., "Half-life of the long-lived ${ }^{99}$ Tc". Phyiscal Review 81 (1951): 741-747.

Friedlander, Gerhart, Kennedy, Joseph W., Miller, Julion Malcolm. Nuclear and Radiochemistry 2nd Ed. New York: John Wiley and Sons, 1966:9.

Gancarz, A., Cowan, G., Curtis, D., Maeck, U. "999'c and Ru migration around the Oklo natural fission reactors". Scientific Basis for Nuclear Waste Management, Vol 2. New York, NY: Plenum, 1980. 601-608.

Henrot, J. "Bioaccumulation and chemical modification of Tc by soil bacteria. Health Phys. 57 (1989): 239-45.

Kenna, B.T. "The search for technetium in nature" J. Chem. Ed. 39 (1962): 436442.

Kenna, B.T., and Kuroda, P.K. "The ratio of induced fission vs. spontaneous fission in pitchblende and natural occurrence of radiochlorine. J. Inorg. Nucl. Chem. 16 (1960): $1-7$.

Kenna, B.T., and Kuroda, P.K. "Technetium in nature". J. Inorg. Nucl. Chem. 26 (1964): 493-499.

Landa, Edward R., Thorvig, (Hart) Lisa, Gast, Robert, G. "Effect of selective dissolution, electrolytes, aeration, and sterilization on technetium-99 sorption by soils". J. Envion. Qual. 6 (2) (1977): 181-187. 
Lathrop, K.A., Atkins, H.L., Becman, M., Hays, M.T., Smith, E.M. "Summary of current radiation dose estimates to normal humans from ${ }^{99 m} \mathrm{Tc}$ as sodium pertechnetate". J. Nucl. Med. 17 (1) (1976): 74-77.

Lee, Suk Y., Bondietti, Ernest A. "Technetium behavior in sulfide and ferrous iron solutions". Mat. Res. Soc. Symp. Proc. 15 (1983): 315-321.

Manakan, Stanley, E. "Complexation by humic substances". Environmental Chemistry 6th Ed. Boca Raton, Florida: Lewis Publishers, 1994.

Meyer, R.J., Oldham, R.D., Larsen, R.P. "Separation and spectrophotometric determination of technetium in fission". Analytical Chemistry 36 No. 10 (1964): 1975-1979.

Miller, P.J., Zittel, H.E. "Spectrophotometric determination of technetium with 1,5diphenylcarbohydrozide". Anal. Chem. 35 (1963): 299-301.

Muenze, R. "Polynuclear ${ }^{99}$ technetium(IV)-citrate complex". Radiochem. Radioanal. Letters 48 (5) (1981): 281-288.

Palmer, Donald A., Meyer, Robert, E. "Adsorption of technetium on selected inorganic ion-exchange materials and on a range of naturally occurring minerals under toxic conditions". J. Inorg. Nucl. Chem. 43 (11) (1981): 2979-2984.

Richards, P., Tucker, W.D., Srivastava, S.C. "Technetium-99m: An Historical Perspective" Int. J. Appl. Radiat. Isot. 33 (1982): 793-799.

Rickard, R.R. "Determination of technetium infission product mixtures". Oak Ridge National Laboratory Master Analytical Manual (1980). 
Salaria, G,B,S, Charles L., Elving, Philip J. "Liquid-liquid extraction of pertechnetate ion with methyltricaprylammonium chloride". Analytical Chemistry $35 \mathrm{Na} 8$ (1963): 983-985.

Soil Survey Staff. "Soil survey manual". U.S. Dept. Agriculture Handbook (18) (1951): 503.

Steigman, J., Eckelman, W.C., The Chemistry of Technetium in Medicine. NAS-NS3204. Washington, D.. National Academy Press, 1992.

Steigman, J. Meinken, G., Richards, P. "The reduction of pertechnetate-99 by stannous chloride: II. The stoichiometry of the reaction in aqueous solutions of several phosphorous (V) compounds". Int. J. Appl. Radiat. Isotopes 29 (1978): 653-660.

Steigman, J., Eckelman, W.C., Meinken, G., Isaacs, H.S., Richards, P. "The chemistry of technetium labeling of radiopharmaceuticals by electrolysis". J. Nucl. Med. 15 (1974): 75-80.

Steigman, J. Meinken, G. Richards, P. "The reduction of pertechnetate-99 by stannous chloride: I. The stoichiometry of the reaction in $\mathrm{HCl}$, in a citrate buffer, and in a DTPA buffer". Int. J. Appl. Radiat. Isotopes 26 (1975): 601609.

Strickert, R., Friedman, A.M., Fried, S. "The sorption of technetium and iodine radioisotopes by various minerals". Nuclear Technology 49 (1980): 253-266.

Todd, David Keith. Groundwater Hydrology 2nd Ed. New York: Wiley and Sons, 1976: 29,30,69. 
Wildung, R.E., McFadden, K.M., and Garland, T.R. "Technetium Sources and Behavior in the Environment". J. Enviorn. Qual. 8 no. 2 (1979): 156-161.

Willard, Hobart H., Merritt, Jr. Lynne L., Dean, John A. "Statistics in measurement of radioactivity". Instrumental Methods of Analysis. 4th Ed. Princeton, New Jersey: D. Van Nostrand Co, Inc., 1965. 


\section{Appendix 1}

Amount of ${ }^{99} \mathrm{Tc}$ Produced from a Patient Dose of 30 Millicuries

1 (Ci) curie ${ }^{99 \mathrm{~m} T c}=0.19$ micrograms ${ }^{997 \mathrm{c}}$ from $-\mathrm{dN} / \mathrm{dt}=\lambda \mathrm{N}$

$1 \mathrm{Ci}^{99} \mathrm{Tc}=58.978$ grams $^{99} \mathrm{Tc}$

$\left(6 \times 10^{6}\right)(0.9)(30$ millicuries $)=1.62 \times 10^{8} \mathrm{mCi}$

$\left(1.62 \times 10^{8} \mathrm{mCi}\right)(1 \mathrm{Ci} / 1000 \mathrm{mCi})=1.62 \times 10^{5} \mathrm{Ci}$

$\left(1.62 \times 10^{5} \mathrm{Ci}\right)\left(0.19 \mu \mathrm{g}{ }^{99} \mathrm{Tc} / \mathrm{Ci}\right)=3.08 \times 10^{4} \mu \mathrm{g}$

$\left(3.08 \times 10^{-2} \mathrm{~g}\right)\left(1 \mathrm{Ci}{ }^{99} \mathrm{Tc} / 58.978 \mathrm{~g}\right)=5.2 \times 10^{-4} \mathrm{Ci}$ 


\section{Appendix II}

Calculation of Specific activity of ${ }^{99} \mathrm{Tc}, \mathrm{N}=\mathrm{N}_{0} \mathrm{e}^{-\lambda t}$,

$\mathrm{N}_{0}=$ atoms present at $\mathrm{t}=0$

$-\mathrm{dN} / \mathrm{dt}=\lambda \mathrm{N}, \mathrm{N}=$ atoms unchanged at time $\mathrm{t}$

$1 \mathrm{Ci}=3.7 \times 10^{10} \mathrm{dps}^{99} \mathrm{Tc}, \mathrm{T}^{1 / 2}=2.13 \times 10^{5} \mathrm{yrs}$ and $\lambda=0.639 / \mathrm{T}^{1 / 2}$

For $1 \mathrm{Ci}$ of ${ }^{99} \mathrm{Tc}$ :

$3.7 \times 10^{10} \mathrm{dps}=(0.693)($ moles $)\left(6.02 \times 10^{23}\right.$ atoms $\left./ \mathrm{mole}\right) /\left(2.13 \times 10^{5} \mathrm{yr}\right)$

$(365 \mathrm{~d} / \mathrm{yr})(24 \mathrm{hr} / \mathrm{d})(60 \mathrm{~min} / \mathrm{hr})(60 \mathrm{sec} / \mathrm{min})$

moles $=0.5957$

(0.5957 moles) (99 grams $/$ mole $)=58.978 \mathrm{gms}{ }^{99} \mathrm{Tc}$

dpm dps Activity Mass Activity/Mass

$2.22 \times 10^{12}$

$3.7 \times 10^{10} 1 \mathrm{Ci}, 58.978 \mathrm{~g}, 1 \mathrm{~g}=0.01695 \mathrm{Ci}$

$2.22 \times 10^{9}$

$3.7 \times 10^{7} 1 \mathrm{mCi}, 58.978 \mathrm{mg}, 1 \mathrm{mg}=0.01695 \mathrm{mCi}$

$2.22 \times 10^{6}$

$3.7 \times 10^{4} 1 \mu \mathrm{Ci}, 58.978 \mu \mathrm{g}, 1 \mu \mathrm{g}=0.01695 \mu \mathrm{Ci}$

$2.22 \times 10^{3}$

$3.7 \times 10^{1} 1 \mathrm{nci}, 58.978 \mathrm{ng}, 1 \mathrm{ng}=0.01695 \mathrm{nci}$

2.22

$3.7 \times 10^{-2} 1 \mathrm{pci}, 58.978 \mathrm{pg}, 1 \mathrm{pg}=0.01695 \mathrm{pci}$ 


\section{Appendix III}

Detection of ${ }^{99} \mathrm{Tc}$ in HPLC U.V. Flow Cell

Assumptions: All ${ }^{99} \mathrm{Tc}$ gets eluted in small volume ( 8 microliters) $A=a b c$ if absorbance $=0.1$ and $\varepsilon=6220 \mathrm{~cm}^{-1} \mathrm{~m}^{-1}$ then the concentration of ${ }^{99} \mathrm{Tc}$ is

$0.1=\left(6220 \mathrm{~cm}^{-1} \mathrm{~m}^{-1}\right)(1 \mathrm{~cm}) \mathrm{C}$

$\mathrm{C}=1.61 \times 10^{-5} \mathrm{M}=\mathrm{gms} / 99 / 8 \times 10^{-6}$ liters

gms $=1.27 \times 10^{-8},\left(1.27 \times 10^{-8} \mathrm{~g}\right)\left(10^{6} \mu \mathrm{g} / \mathrm{g}\right)=1.27 \times 10^{-2} \mu \mathrm{g}$ and

$\left(1.27 \times 10^{-2} \mu \mathrm{g}\right)\left(1 \mu \mathrm{Ci}^{99} \mathrm{Tc} / 58.978 \mu \mathrm{g}\right)=2.16 \times 10^{-4}$ uci

or 216 picocuries 
Appendix IV

Isotopes Produced in Irradiation and Production of ${ }^{95 \mathrm{~m}} \mathrm{Tc}$ Time of assay $4 / 21 / 95$

\begin{tabular}{|c|c|c|c|}
\hline & $T^{1} 1 / 2$ & act. produced & total act. \\
\hline${ }^{95 \mathrm{~m}} \mathrm{TC}$ & $61 d$ & $2.43 \mathrm{mCi} / \mathrm{ml}$ & $14.31 \mathrm{mCi}$ \\
\hline${ }^{959} \mathrm{Tc}$ & $20 \mathrm{hr}$ & $3.67 \mathrm{mCi} / \mathrm{ml}$ & $21.56 \mathrm{mCi}$ \\
\hline${ }^{969} \mathrm{Tc}$ & $4.28 \mathrm{~d}$ & $13.66 \mathrm{mCi} / \mathrm{ml}$ & $80.31 \mathrm{mCi}$ \\
\hline \multicolumn{4}{|c|}{ other isotopes of lesser interest because of half-life } \\
\hline${ }^{96 \mathrm{~m}} \mathrm{Tc}$ & $51.5 \mathrm{mi}$ & & \\
\hline${ }^{949} \mathrm{TC}$ & $4.88 \mathrm{hr}$ & & \\
\hline
\end{tabular}


